\title{
La corrupción urbanística: Estrategias de análisis.
}

\author{
José Luis Díez Ripollés ${ }^{1}$ y Alejandra Gómez-Céspedes ${ }^{2}$ \\ Universidad de Málaga
}

\begin{abstract}
RESUMEN
Hipótesis de este estudio es que el asentamiento de la corrupción urbanística en un determinado territorio resulta favorecido por la presencia simultánea en esa área geográfica de determinados indicadores socioeconómicos. Si los poderes públicos ejercen una escasa influencia sobre esos indicadores, la corrupción urbanística tiende a perdurar o a agravarse. Si, por el contrario, los poderes públicos inciden significativamente en un número crítico de esos factores socioeconómicos, cabe esperar que la corrupción urbanística acabe descendiendo de forma apreciable en ese territorio. En estos momentos no estamos en condiciones de verificar la hipótesis apuntada. Sin embargo, a efectos de su posible confirmación transcurrido un tiempo suficiente, pretendemos en este trabajo: 1. Aportar información sobre la efectiva presencia en la Costa del Sol (Málaga) de ese conjunto de indicadores socioeconómicos. 2. Documentar un cambio de tendencia, más intervencionista, en los poderes públicos a la hora de abordar el fenómeno.
\end{abstract}

\begin{abstract}
The hypothesis for this study is that the settlement of planning and construction related corruption in a specific geographical region is favoured by the simultaneous occurrence in that region of particular socioeconomic indicators. If state power exerts only a minor influence upon those indicators, then corruption tends to persist even to worsen. On the other hand, if state power has an effective influence on a significant number of those indicators, one would expect corruption to reduce appreciably in that region. At this point in time we are not able to test the above mentioned hypothesis. A necessary time has to elapse before we reach that point. Nevertheless, the intention of this article is twofold: (1) To provide relevant data on the actual occurrence of a set of socioeconomic indicators across the Spanish Costa del Sol (Malaga). (2) To indicate a positive change of tendency towards more state intervention in the context of planning and construction related corruption.
\end{abstract}

\footnotetext{
${ }^{1}$ Catedrático de Derecho Penal y Director del Instituto andaluz interuniversitario de Criminología en la Universidad de Málaga.

${ }^{2}$ Criminóloga especializada en delincuencia económica y organizada, profesora investigadora del Instituto andaluz interuniversitario de Criminología de la Universidad de Málaga.
}

Revista Española de Investigación Criminológica

Artículo 5, Número 6 (2008) $\quad$ www.criminología.net

ISSN: 1696-9219 


\section{INTRODUCCIÓN}

El fenómeno de la corrupción urbanística ha sido una práctica recurrente en la historia reciente de España. ${ }^{3}$ Sin embargo, no ha sido hasta este último lustro que el fenómeno ha pasado a considerarse de notoria gravedad desde instancias sociales, políticas y administrativas.

Por otro lado el debate de la corrupción en general y de la corrupción urbanística en particular ha sacado a la luz un abanico de conflictos paralelos de suma importancia. Cabe destacar los relativos a la rendición de cuentas políticas y administrativas; la financiación de partidos políticos; la transparencia y acceso a la información pública; los modelos de desarrollo urbanístico y desarrollo turístico; el encarecimiento de la vivienda; la evasión fiscal y el blanqueo de capitales; la indefensión a la que se ven sometidos muchos ciudadanos; y la penetración en el sector inmobiliario de la delincuencia organizada.

Un abordaje del problema desde posiciones multidisciplinares parece ineludible para encontrar soluciones a corto, mediano y largo plazo. El enfoque criminológico que presentamos puede aportar elementos de análisis significativos.

\section{OBJETIVO}

El punto de partida de nuestro trabajo es una hipótesis que no estamos en condiciones de verificar por el momento, pero que, a efectos de una posible confirmación más adelante, pretendemos ir dotando de la información imprescindible para su futura verificación.

La hipótesis vendría a decir lo siguiente:

El asentamiento de la corrupción urbanística en un determinado territorio resulta favorecido por la presencia simultánea en esa área geográfica de determinados indicadores socioeconómicos relevantes. Si los poderes públicos inciden significativamente en un número crítico de esas realidades socioeconómicas, la corrupción urbanística acaba descendiendo de forma apreciable en ese territorio.

Frente a esa hipótesis existen otras alternativas:

\footnotetext{
${ }^{3}$ Ver, entre otros: (i) Alcaraz Ramos, M. (Dir.), El Estado de Derecho frente a la corrupción urbanística. La Ley, 2007. (ii) Fundación Alternativas, Urbanismo y democracia: Alternativas para evitar la corrupción, 2007. (iii) Greenpeace, Informes Destrucción a toda costa, Años 2001 - 2007.
}

Revista Española de Investigación Criminológica

Artículo 5, Número 6 (2008) $\quad$ www.criminología.net

ISSN: $1696-9219$ 
Una afirmaría que son las condiciones económicas generales las que condicionan decisivamente la evolución de la corrupción urbanística. Otra sostendría que son las necesidades específicas de lucro de ciertos agentes económicos, legales o ilegales, las que desencadenan fenómenos de corrupción urbanística. A esta y otras hipótesis les sería común la idea de la escasa influencia de las actuaciones específicas de los poderes públicos contra la corrupción urbanística.

A los efectos de preparar la verificación de la hipótesis de partida, en el presente trabajo se pretende específicamente:

1. Aportar información sobre la efectiva presencia en la Costa del Sol (Málaga) de ese conjunto de indicadores socioeconómicos cuya concurrencia simultánea estimamos que promueve la consolidación de la corrupción urbanística.

2. Documentar un cambio de tendencia, más intervencionista, en los poderes públicos a la hora de abordar el fenómeno y, consecuentemente, de incidir sobre un número significativo de esas variables socioeconómicas.

Tras un plazo de tiempo hasta ahora no transcurrido, y persistente la nueva actitud de los poderes públicos, será la hora de verificar si esa actitud más intervencionista produce un descenso apreciable de la corrupción urbanística en el territorio estudiado.

En este artículo no pretendemos criminalizar la actividad urbanística de la Costa del Sol, sino poner de manifiesto una serie de datos que, en su conjunto, deberían alertar sobre el hecho de que, de no adecuarse los controles, una actividad urbanística de veloz crecimiento lleva aparejada valiosas oportunidades para el desarrollo y arraigo de prácticas corruptas que sirven de asiento a redes de delincuencia económica organizada en la zona.

\section{DELINCUENCIA ECONÓMICA, DELINCUENCIA ORGANIZADA Y CORRUPCIÓN URBANÍSTICA}

A pesar de que la delincuencia económica no es un fenómeno nuevo, puede afirmarse que la actitud europea de denuncia y puesta de relieve sí es una postura reciente.

Hasta hace muy poco tiempo existía una especie de indulgencia, en algunos casos incluso una inmunidad de facto, de cara a la delincuencia económica, que era habitualmente definida como una delincuencia de cuello blanco. La delincuencia económica era considerada falsamente menos peligrosa para la sociedad o, cuando menos, menos perjudicial que la delincuencia tradicional, probablemente porque era

Revista Española de Investigación Criminológica

Artículo 5, Número 6 (2008) $\quad$ www.criminología.net

ISSN: 1696-9219 
difícil de advertir su amenaza. En todo caso, la estigmatización de los delincuentes económicos era reducida, ya que era compensada por cierto grado de reputación y prestigio.

Probablemente no fue hasta la salida a la luz de la quiebra fraudulenta de la empresa italiana Parmalat, a finales de 2003, que el triángulo institucional de la Unión Europea ${ }^{4}$ se dio cuenta de las ruinosas consecuencias que suponía para miles de personas el mayor escándalo financiero de Europa.

Del escándalo Parmalat pueden extraerse, quizás, tres importantes conclusiones: (i) Que los delitos económicos de gran magnitud son también posibles en Europa y no sólo en Estado Unidos. (ii) Que existen importantes deficiencias gubernamentales en la supervisión patrimonial de las empresas y, (iii) que hay que modificar actitudes preconcebidas y entender que la delincuencia económica grave no sólo la cometen delincuentes profesionales sino también personas respetables en el ejercicio de su profesión.

No es fácil definir la delincuencia económica. A la fecha, no se ha alcanzado un acuerdo internacional sobre la definición del concepto. Diferentes países europeos utilizan distintas definiciones. Incluso en algunos países los delitos económicos son considerados meras infracciones administrativas.

No obstante, en el año 1981, el Consejo de Europa ${ }^{5}$ hacía un listado de delitos que consideraba deberían calificarse como delitos de delincuencia económica. Estos delitos incluían distintos tipos de fraudes, delitos fiscales, relativos a sociedades tapadera, relativos al mercado de valores o a la alteración de precios en concursos y subastas públicas, entre otros.

En general, el Consejo de Europa observó que las consecuencias negativas de la delincuencia económica superaban la mera victimización de individuos e iban más allá de cualquier daño material tangible. En concreto, se ha reconocido que la delincuencia económica:

- Afecta a un gran número de personas, a la sociedad y al Estado en general.

- Daña el funcionamiento de las economías a nivel nacional o internacional.

- Socava la confianza y la seguridad que los individuos tienen en el sistema económico y/o democrático.

\footnotetext{
${ }^{4}$ La Comisión, el Parlamento y el Consejo.

${ }^{5}$ Recomendación del Consejo de Europa R(81) 12 sobre Delincuencia Económica, adoptada por el Comité de Ministros el 25 de junio de 1981.
}

Revista Española de Investigación Criminológica 
En cuanto a la delincuencia organizada, resulta difícil definirla con claridad e identificar sus elementos característicos, puesto que adopta formas muy versátiles y se aprovecha a fondo de la universalización y del uso de modernas y sofisticadas tecnologías. No obstante, la Convención de las Naciones Unidas contra la delincuencia organizada transnacional ${ }^{6}$, en su Artículo 2, define lo que deberá entenderse por grupo delictivo organizado:

"Se entenderá un grupo estructurado ${ }^{7}$ de tres o más personas que exista durante cierto tiempo y que actúe concertadamente con el propósito de cometer uno o más delitos graves ${ }^{8}$ o delitos tipificados con arreglo a la presente Convención con miras a obtener, directa o indirectamente, un beneficio económico u otro beneficio de orden material".

Por otro lado, se observa con preocupación que la delincuencia económica y la delincuencia organizada tienden a entrelazarse en muchas áreas, como por ejemplo en la evasión fiscal, la adjudicación de concursos públicos, las privatizaciones, las falsificaciones, los crímenes medioambientales, o el fraude de tarjetas de crédito. Sus necesidades, por lo demás, coinciden, dado que tanto la delincuencia económica como la delincuencia organizada generan grandes fortunas que no se gastan inmediatamente y requieren ser blanqueadas.

Tampoco hay que pasar por alto que ambas clases de delincuencia se sirven de la corrupción administrativa y política para lograr sus fines y, por ende, fracturan el Estado de Derecho y el buen gobierno.

Dicho esto, conviene destacar que el término corrupción es una calificación omnicomprensiva que abraza un gran número de supuestos. En el caso de la corrupción urbanística podemos referirnos por ejemplo a:

- Un alcalde que acepta un soborno o exige una dádiva a cambio de una reclasificación de suelo.

- Un alcalde que incumple un plan general porque considera que conceder licencia para un macro-proyecto hotelero o de ocio generará empleo en la zona.

\footnotetext{
${ }^{6}$ También conocida como Convención de Palermo, y que entró en vigor el 29 de septiembre de 2003. El Reino de España la firmó el 13 de diciembre de 2000 y la ratificó el 1 de marzo de 2002. Ver, Oficina de las Naciones Unidas contra la Droga y el Delito: http://www.unodc.org

${ }^{7}$ Por "grupo estructurado" se entenderá un grupo no formado fortuitamente para la comisión inmediata de un delito, en el que no necesariamente se haya asignado a sus miembros funciones formalmente definidas ni haya continuidad en la condición de miembro ni exista una estructura desarrollada.

${ }^{8}$ Por "delito grave" se entenderá la conducta que constituya un delito punible con una privación de libertad de al menos cuatro años de límite máximo o con una pena más grave.
} 
- Un alcalde que favorece a empresas mediante el uso parcial de información relativa a la publicación de concursos y subastas.

- Cualquier cargo político que actúe de forma que en la elaboración de normas o adopción de decisiones favorezca a grupos que hayan financiado a su partido.

- Cualquier autoridad o funcionario que abusen de su cargo para obtener descuentos, regalos o ventajas.

Si bien la especificidad de la corrupción urbanística es importante, sería conveniente que en el plano criminológico se renunciara a tratar a la delincuencia económica, la delincuencia organizada y la corrupción pública como tres fenómenos independientes.

Sería más realista fundir estos conceptos en una categoría mucho más amplia. Es decir, estaríamos hablando de una delincuencia socioeconómica de la cual la delincuencia organizada o la corrupción urbanística o de otro tipo, serían meras subdivisiones.

Por supuesto que habría que destacar ciertas diferencias, como por ejemplo, en los objetivos de cada tipología. Las empresas se establecen, a priori, para gestionar negocios legales aunque acaben realizando actividades ilegales. Los grupos delictivos organizados se montan con el propósito de cometer delitos buscando siempre el lucro como fin principal. Y, por último, los funcionarios públicos que trabajan para el gobierno y son garantes del cumplimiento de las leyes en ocasiones pueden abusar sus cargos para lograr beneficios privados directos (sobresueldo, ascensión en la carrera política o multiplicación de la red de contactos) o indirectos (beneficios para el partido político al que pertenecen o favores para amigos y familiares).

\section{CONDICIONES QUE FAVORECEN EL ASENTAMIENTO DE LA CORRUPCIÓN URBANÍSTICA: EL CASO DE LA COSTA DEL SOL}

Quizás ningún otro mercado español solapa tanto la legalidad y la ilegalidad como lo hace el sector de la actividad urbanística. En la mayoría de los casos no es fácil distinguir la criminalidad del sector, pues para eso tiene que haber víctimas dispuestas a denunciar las irregularidades, cosa que se vuelve harto difícil cuando no existe, por un lado, una tradición de prevención y persecución de delitos socioeconómicos y, por el otro, la capacidad y/o deseo de proteger a los denunciantes.

Parece indiscutible, tras las intervenciones policiales y judiciales acaecidas en los últimos años, que el rápido crecimiento de la actividad urbanística en la Costa del Sol ha creado un favorable caldo de cultivo para el desarrollo de una notable delincuencia

Revista Española de Investigación Criminológica

Artículo 5, Número 6 (2008) www.criminología.net

ISSN: $1696-9219$ 
socioeconómica en la zona. Pues bien, creemos que ello se debe en buena parte a la concurrencia en este territorio, al menos desde mediados de los años 90 del pasado siglo y hasta bien entrados en la primera década del siglo XXI, de una serie de condiciones que favorecen el asentamiento de prácticas delictivas económicas organizadas que se sirven de la corrupción urbanística. Estas son las condiciones:

\subsection{BUENAS OPORTUNIDADES DE NEGOCIO EN LA ACTIVIDAD}

\section{INMOBILIARIA}

Sería bueno empezar este apartado indicando el cambio de ciclo inmobiliario que se ha vivido a partir del año 2007, intensificado incluso con la crisis estadounidense de las hipotecas de alto riesgo. Desde entonces, la construcción, promoción y compraventa de viviendas en España viene sufriendo una corrección gradual a la baja.

Nuestra intención no es pronosticar si los síntomas de agotamiento que presenta el mercado nacional desembocarán o no en una recesión económica. $9{ }^{10}$ Lo que a nosotros nos interesa es explicar las consecuencias que ha tenido a nivel local la expansión tan acelerada del sector de la construcción y del mercado inmobiliario.

En los últimos años, el acelerado auge de la vivienda en España ha sido, curiosamente, tanto motivo de alegría como de discordia. Por un lado, la actividad urbanística se ha consolidado como motor fundamental de la economía española contemporánea. Por otra parte, esa prosperidad se ha visto empañada por la manera, muchas veces irregular, en que se ha venido practicando. Con esto no intentamos afirmar que toda la actividad urbanística se haya realizado de forma irregular. No obstante, en regiones donde el crecimiento ha sido exponencial, vale la pena detenerse a reflexionar sobre algunos datos interesantes.

Según el Ministerio de Vivienda ${ }^{11}$, el número de viviendas libres iniciadas en España pasó de 161.066 en 1991 a 664.924 en 2006. Salvo los años 1995 y 1996, la tendencia en la evolución del número de viviendas iniciadas ha sido al alza en los últimos 15 años. Es más, desde el año 2003 se inicia la construcción en España de más de medio millón de viviendas al año.

\footnotetext{
9 Aunque algunos análisis apuntan en esa dirección... The Economist, Dangers ahead [Peligros por delante], Febrero $14,2008$.

${ }^{10}$ Ver también, El País 19/02/2008, La compra de viviendas nuevas para especular se frena en seco, de Lluís Pellicer y El País 31/03/2008, Las ventas de casas caen un 24\% y se construye la mitad que en 2006, de Diego Narváez.

${ }^{11}$ Ministerio de Vivienda, Número de viviendas libres iniciadas: Serie 1991-2006, Viviendas libres por comunidades autónomas y provincias, Madrid, 2007.
}

Revista Española de Investigación Criminológica

Artículo 5, Número 6 (2008) $\quad$ www.criminología.net

ISSN: $1696-9219$ 
Esa cifra puede significar 'mucho' o 'poco' dependiendo de la provincia que se observe, y del punto de partida en el inicio del ciclo. Por ejemplo, la provincia de Albacete pasó de 1.205 viviendas iniciadas en 1991 a 3.803 viviendas en el año 2003. Valencia inició la construcción de 6.634 viviendas en 1991, mientras en el año 2003 inició un total de 20.758. La Comunidad de Madrid pasó de 15.334 en 1991 a 40.226 en 2003.

En cuanto a la provincia de Málaga, se iniciaron 5.630 viviendas en 1991 y, doce años más tarde, esa cifra se había multiplicado 14 veces, ya que en 2003 se iniciaron 83.274 viviendas. Este año constituye para Málaga el punto de inflexión en su tendencia alcista. A partir de entonces, pierde el papel protagonista en el número de viviendas iniciadas.

Pero no podemos olvidar que entre 1999 y 2003 Málaga fue la provincia en donde más viviendas se iniciaron de todo el territorio español. Superó incluso a provincias como Barcelona o a la misma Comunidad de Madrid. En ese periodo de cinco años, el total de viviendas iniciadas en Málaga fue de 324.666, mientras que en Barcelona se iniciaron 224.854 y en la Comunidad de Madrid 198.651. En el año 2003, el 30\% de todas las viviendas comenzadas en España se iniciaron en Málaga, Barcelona y la Comunidad de Madrid. El año 2004 indica un cambio de tendencia, y el mayor número de viviendas iniciadas se efectúa en la Comunidad de Madrid (60.113), seguida por Barcelona (48.544) y Alicante (44.224). La provincia de Málaga pasa al cuarto lugar (42.214). Para el año 2006, Málaga cae al sexto puesto en el ranking de viviendas iniciadas, quedando las posiciones de la siguiente manera: Comunidad de Madrid (51.586), Barcelona (51.531), Región de Murcia (37.058), Alicante (36.537), Valencia (34.291) y Málaga (32.794).

La intensa actividad urbanística registrada en Málaga hasta 2003 no se correspondía con el crecimiento de su población, incluso considerando a la población transeúnte (Gráfico No. 1). De tal forma que el incremento en el número de viviendas iniciadas sólo podría explicarse recurriendo a factores externos, como la especulación. A tales efectos, la mayoría de los ayuntamientos costeros de Málaga se sumergieron en una dinámica de laxitud de controles de la actividad urbanística, la cual trajo consigo graves consecuencias, que van desde un incremento anormal de los precios de la vivienda, muy por encima del Índice de Precios al Consumo (IPC), pasando por una grave e 
irrecuperable destrucción del medio ambiente, y culminando en la disolución de un ayuntamiento, el de Marbella, a causa de una extendida red de corrupción política. ${ }^{12}$

Gráfico No. 1. Relación entre población y viviendas visadas en 2003

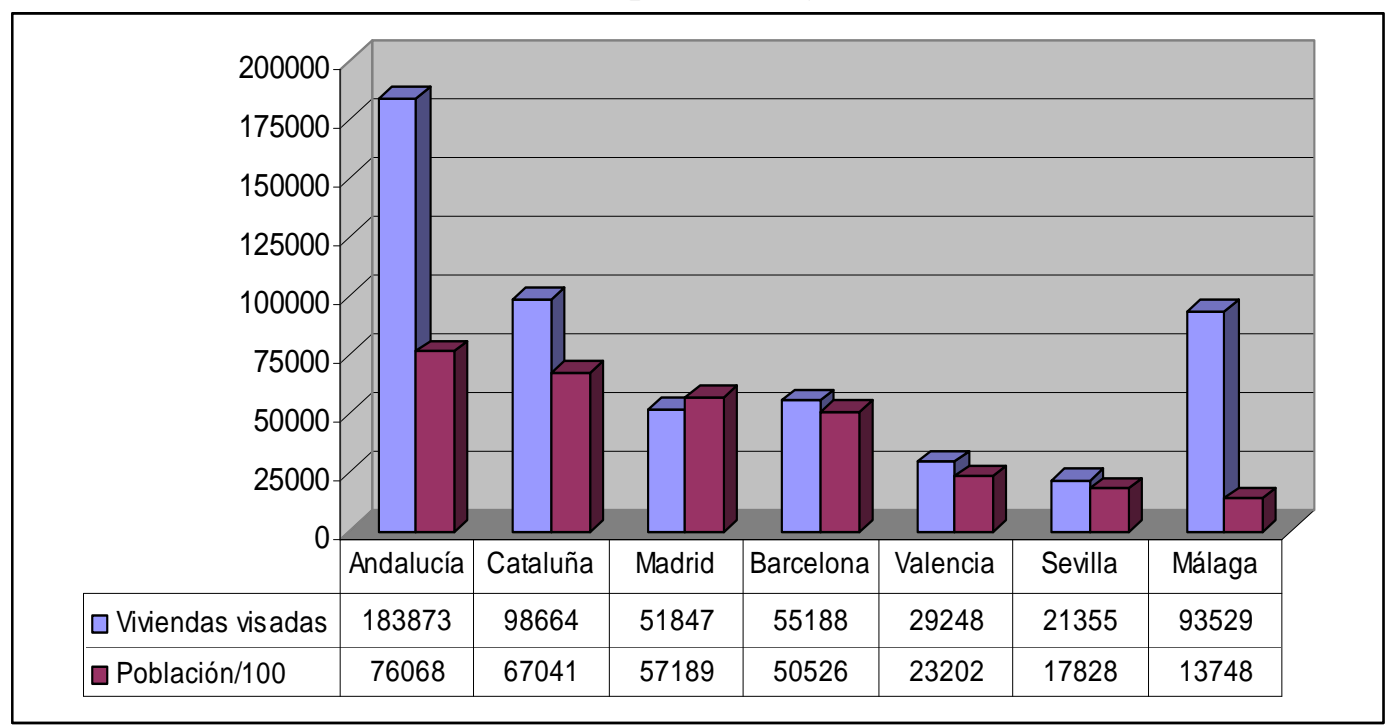

Fuente: Elaboración propia a partir de datos del Instituto Nacional de Estadística (INE)

\subsection{PRESENCIA DE IMPORTANTES ACTIVIDADES DE DELINCUENCIA ORGANIZADA}

\section{No relacionada directamente con la actividad urbanística}

Sin lugar a dudas la principal actividad delictiva perpetrada por grupos delictivos organizados en España es el tráfico ilegal de drogas. ${ }^{13}$ No obstante, la delincuencia organizada se sirve también de otras actividades como, por ejemplo, el robo e importación/exportación ilegal de vehículos, el tráfico de inmigrantes ilegales, la trata de seres humanos (especialmente mujeres y niños), el tráfico ilegal de armas, el robo residencial, el secuestro, la explotación de la prostitución, el fraude financiero o el blanqueo de capitales.

Sin embargo, en el caso de España es muy difícil acceder a los datos y estadísticas oficiales en materia de delincuencia organizada. Si bien es cierto que las estadísticas

12 Real Decreto 421/2006, de 7 de abril, por el que se dispone la disolución del Ayuntamiento de Marbella. BOE No. 84, 08/04/2006.

${ }^{13}$ Fiscalía General del Estado, Memoria de la Fiscalía Especial para la Represión del Tráfico Ilegal de Drogas, Madrid, 2004

Revista Española de Investigación Criminológica

Artículo 5, Número 6 (2008) $\quad$ www.criminología.net

ISSN: $1696-9219$ 
policiales, judiciales y penitenciarias están al alcance del ciudadano, éstas no especifican si ciertas actividades delictivas como, por ejemplo, el tráfico ilícito de drogas se realizan por individuos o por grupos delictivos organizados. Así, los hechos delictivos conocidos o las detenciones por tráfico de drogas no diferencian en función de si se ha incidido sobre comportamientos individuales o sobre organizaciones, y menos sobre las características de éstas. Y si eso sucede con los datos sobre el tráfico ilícito de drogas tóxicas, estupefacientes y sustancias psicotrópicas, que son los que mejor pueden ilustrar el panorama en materia de delincuencia organizada en España, qué decir del resto de actividades delictivas organizadas.

En 2004 los delitos de tráfico de drogas conocidos en España supusieron el 1,19\% de todos los delitos conocidos - con exclusión de faltas-. En Andalucía esa cifra fue del 1,54\%, en la Costa del Sol ampliada - Málaga, Cádiz y Granada - del 2,13\%, y en Málaga del 1,6\%.

En 2004 las detenciones por tráfico de drogas supusieron en España el 6,03\% del total de detenciones por delito - sin inclusión de faltas -. En Andalucía el porcentaje asciende al 8,08\% del mismo total andaluz. En la Costa del Sol ampliada constituye un 10,55\%, y en Málaga un $7,72 \%^{14}$.

En 2004, el porcentaje de detenciones por tráfico de drogas de extranjeros en España era del 33,91 \% (4838) del total. En Andalucía constituían el 28, 4 \% (1135) del total. En la Costa del Sol ampliada son un 28,9 \% (804) del total. En Málaga son un 36,33\% (355) del total ${ }^{15}$.

En 2004 de los extranjeros detenidos por tráfico de drogas en España el 21,48\% procedían de Europa, el 51,41 de África, el 26,02\% de América, y el 1,10 de Asia. Por nacionalidades, el 40,61\% eran marroquíes, el 12,73\% colombianos, el 4,86\% franceses, el 3,41\% argelinos y el 3,22\% británicos, nacionalidades que suman el 64,83\% del total. Por otro lado, los datos en materia de incautación de droga se consideran como indicadores directos de actividades de narcotráfico. Es cierto que también se ha sugerido que dichos datos son un reflejo del éxito de actuaciones policiales. Ambas interpretaciones merecen ser consideradas y no es sino hasta que se computan otros valores que la imagen empieza a ser más nítida.

\footnotetext{
${ }^{14}$ García España, E. y Pérez Jiménez, F., Informe del Observatorio de la Delincuencia en Andalucía Seguridad ciudadana y actividades policiales, IAIC-Fundación El Monte Málaga, 2005. ${ }^{15}$ Ibid.
}

Revista Española de Investigación Criminológica 
En el año 2006, España se convirtió en el primer país a través del cual se introducía cocaína en Europa. Es decir, el $40 \%$ de todas las incautaciones de cocaína en Europa se llevaron a cabo en España. A nivel mundial, España fue el cuarto país en incautaciones de cocaína, situándose por detrás de Colombia, Estados Unidos y Venezuela (en ese orden) y por delante de países como México, Brasil o Bolivia. ${ }^{16}$ España se ha hecho con este papel protagonista en la última década, pues las cantidades de cocaína incautadas se multiplicaron por siete en el periodo 1995 - 2005. Aparentemente, la cocaína que llega actualmente a España ha transitado previamente por Sudamérica (principalmente por Ecuador y Venezuela) y África (especialmente por Senegal y Cabo Verde). Cuando llega a España se traslada primordialmente a Francia y al Reino Unido. Tradicionalmente, la droga llegaba a las costas de Galicia, pero en los últimos años el lugar en donde más cocaína se interviene en España es en alta mar, que alcanza el 66\% del total. ${ }^{17}$ Por proximidad, a los puertos donde se trasladan esas incautaciones son Andalucía, Baleares y Canarias, ${ }^{18}$ lugares que coinciden, muchas veces, con las rutas de importación de la resina de cannabis o hachís.

Por lo que respecta al hachís, en el año 2004 se batieron todos los registros en incautaciones de hachís a nivel mundial. Sólo en tres regiones se incautó el 99\%: En Europa occidental y central, el 74\%; en el cercano y medio Oriente así como en Asia sudoccidental, el 18\% y en el norte de África el 7\%. ${ }^{19}$ En España se incautaron cerca de 800 toneladas ese mismo año. ${ }^{20}$

En el año 2006, más del 50\% de todo el hachís incautado en el mundo se incautó en España, que es seguida muy de lejos por Pakistán (7\%) y Marruecos (7\%). ${ }^{21}$ Del total incautado en España en 2006 (459.267 Kg.) el 55\% se intervino en Andalucía, seguido por Valencia donde se incautó un 19\%, Murcia, con un 14\% y Cataluña con un $7 \%$, correspondiendo al resto otro 7 por $100 .^{22}$

Cuando no se cuenta con muchos datos estadísticos, es importante conocer los precios y/o la pureza de la droga en el mercado. Si el aumento de incautaciones correlaciona con una subida en los precios, entonces estamos frente a una constricción del mercado inducida por operativos policiales. Si, por el contrario, el aumento de incautaciones

\footnotetext{
${ }^{16}$ Naciones Unidas, Informe Mundial sobre Droga, Oficina para la Droga y el Delito, Viena, 2007.

${ }^{17}$ Fiscalía General del Estado, Memoria, Madrid, 2007.

${ }^{18}$ Naciones Unidas, Informe Mundial sobre Droga, Oficina para la Droga y el Delito, Viena, 2007.

${ }^{19}$ Naciones Unidas, Informe Mundial sobre Droga, Oficina para la Droga y el Delito, Viena, 2006.

${ }^{20}$ Ministerio del Interior, Anuario Estadístico, Madrid, 2005.

${ }^{21}$ Naciones Unidas, Informe Mundial sobre Droga, Oficina para la Droga y el Delito, Viena, 2007.

${ }^{22}$ Fiscalía General del Estado, Memoria, Madrid, 2007
}

Revista Española de Investigación Criminológica 
lleva aparejado un descenso o una constancia en los precios, estamos hablando de un mercado caracterizado por una mayor oferta.

Hablando de cocaína, el Informe Mundial sobre Droga de las Naciones Unidas ${ }^{23}$ del año 2005 apuntaba que los precios de la droga (especialmente cocaína) en Europa, no habían variado significativamente en la última década. También advertía que la pureza de la cocaína incautada continuaba siendo alta. Así es que lejos de considerar las incautaciones como un éxito sin matices de los Cuerpos y Fuerzas de Seguridad del Estado, deberíamos lamentar el incremento de la oferta de cocaína en el mercado europeo.

\section{Relacionada directamente con la actividad urbanística}

Como se mencionaba anteriormente, es difícil tener acceso a estadísticas oficiales sobre delincuencia organizada en España. Sin embargo, pueden distinguirse ciertas pautas si se hace un seguimiento continuado de los comunicados de prensa publicados por el Ministerio del Interior.

Siguiendo esta metodología, observamos un gran número de actuaciones policiales destinadas a desmantelar organizaciones delictivas inmersas, en mayor o menor escala, en la actividad urbanística de la Costa del Sol.

Algunos ejemplos son los siguientes:

\section{Operación Delfín ${ }^{24}$}

En su segunda fase, la Policía Nacional detuvo a cuatro personas integrantes de la estructura financiera utilizada por diversas organizaciones de narcotraficantes para el blanqueo de sus ganancias. Una de esas organizaciones criminales, dedicada al tráfico de cocaína, estaba liderada por un ciudadano italiano afincado en España. Las ganancias que obtenía a través de la droga las canalizaba hacia la inversión inmobiliaria en la Costa del Sol, además de hacia otros países como Holanda y Brasil. Entre las personas que actuaban como testaferros se detuvo a familiares del líder de la organización, ya que figuraban como titulares registrales de importantes propiedades. Además formaban parte de los órganos de administración y accionariado de sociedades legalmente constituidas en España y en otros países considerados paraísos fiscales, como las

\footnotetext{
${ }^{23}$ Naciones Unidas, Informe Mundial sobre Droga, Oficina para la Droga y el Delito, Viena, 2006.

${ }^{24}$ Dirección General de la Policía y de la Guardia Civil, Nota de prensa, Madrid, 26 de octubre de 2006.
}

Revista Española de Investigación Criminológica

Artículo 5, Número 6 (2008) $\quad$ www.criminología.net

ISSN: $1696-9219$ 
Antillas Holandesas o Gibraltar. Para la conversión y transformación de los beneficios la organización contaba con el diseño de un entramado societario integrado por más de cincuenta sociedades mercantiles, y tenía numerosas cuentas y productos bancarios. Para gestionar todo la organización disponía de un gestor inmobiliario, quien regentaba dos despachos en la localidad malagueña de Estepona. Esta persona, además de prestar el asesoramiento y la colaboración necesaria, participaba de forma directa en la adquisición y administración de los bienes propiedad de la organización. Concretamente llegó a adquirir más de 20 inmuebles en la zona de Estepona, además de varias viviendas unifamiliares de alto nivel y 15 locales comerciales.

\section{Operación Boxer ${ }^{25}$}

Agentes de la Dirección General de la Policía pertenecientes a la UDYCO Costa del Sol de la Comisaría provincial de Málaga, en colaboración con la UDYCO de la Jefatura superior de Policía de Madrid, con el Grupo de estupefacientes de la Comisaría provincial de Huelva y el (hoy extinto) "Nacional Crime Squad" británico, desarticularon una organización de traficantes de hachís a gran escala que operaba de forma simultánea en España y Gran Bretaña y que culminó con la detención de 34 personas de nacionalidades británica y española. Las investigaciones desarrolladas en Málaga determinaron que los principales miembros de la organización estaban asentados en la localidad de Marbella con una doble misión: por una parte la adquisición de resina de cannabis, la preparación para su ocultación, y el envío al Reino Unido, en donde era distribuida al por menor entre pequeños consumidores. Y por otro lado, la utilización de sociedades inmobiliarias, que permitían canalizar los beneficios económicos provenientes del narcotráfico. Una de las mayores dificultades con las que se enfrentó el equipo de investigación fue la buena preparación de algunos de sus dirigentes: un ex-policía inglés, un ex-marine de la armada británica y un ex-militar profesional que aleccionaban a los demás integrantes sobre las técnicas utilizadas habitualmente por la policía, dificultando considerablemente la operatividad policial.

\footnotetext{
${ }^{25}$ Dirección General de la Policía, Nota de prensa, 28 de enero de 2006.
} 


\section{Operación Turrón ${ }^{26}$}

Agentes de la Dirección general de la Policía, junto con la Unidad combinada de Vigilancia aduanera y el apoyo de la Dirección central de Tráfico de estupefacientes de la Policía judicial de Portugal, desarrollaron en la Costa del Sol una nueva operación contra el blanqueo de capitales provenientes del narcotráfico. Esta operación supuso la detención de los integrantes de una organización dedicada a darle apariencia legal a las ganancias de un grupo de narcotraficantes portugueses. Se estima que el dinero destinado por los traficantes a la construcción inmobiliaria ascendía a 40 millones de euros. Entre los detenidos se encontraba la hija del líder de los narcotraficantes y el abogado (afincado en Marbella) que se encargaba de gestionar varias sociedades mercantiles dedicadas a la promoción inmobiliaria. La autoridad judicial decretó el bloqueo de los productos financieros de la organización y también dictó mandamientos de embargo y prohibición de enajenación sobre dos urbanizaciones de lujo (que sumaban un total de 132 apartamentos) ubicadas en la localidad de Mijas-Costa.

\section{Operación Sugar ${ }^{27}$}

Agentes de la Dirección general de la Policía adscritos al Grupo GRECO, junto con la Brigada de investigación económica y financiera de la Comisaría general de Policía Judicial, bajo la coordinación de la Fiscalía Antidroga y del Juzgado central de Instrucción número 3 de la Audiencia Nacional, llevaron a cabo una operación contra una organización de ciudadanos británicos radicados en la Costa del Sol. Estas personas llevaban un alto nivel de vida y ocupaban viviendas de lujo en las mejores urbanizaciones caracterizadas por altas medidas de seguridad. Se bloquearon bienes en cuatro registros de la propiedad de distintos lugares de España, valorados en decenas de millones de euros. También se inmovilizaron cuentas bancarias en tres entidades españolas. En total se estima que el dinero manejado podría alcanzar unos cincuenta millones de euros. El responsable de blanquear las ganancias de la organización era un ciudadano británico de origen pakistaní afincado en una villa de Marbella. La investigación ha permitido conocer numerosas inversiones inmobiliarias en las que se utilizaban grandes cantidades de dinero en efectivo y se recurría a préstamos

\footnotetext{
${ }^{26}$ Dirección General de la Policía, Nota de prensa, 7 de octubre de 2005.

${ }^{27}$ Dirección General de la Policía, Nota de prensa, 14 de julio de 2005.
}

Revista Española de Investigación Criminológica

Artículo 5, Número 6 (2008) $\quad$ www.criminología.net

ISSN: $1696-9219$ 
hipotecarios que sobrevaloraban las propiedades para así poder aumentar las cantidades blanqueadas.

\section{Grupo de Mounir Abdelkader Mohamed E. ${ }^{28}$}

Agentes de la Dirección General de la Policía adscritos a la UDYCO Central, Sección de Investigación Patrimonial, en colaboración con los Grupos de Respuesta Especial contra el Crimen Organizado (GRECO), descubrieron una organización compuesta por varias redes dedicadas al tráfico de hachís a gran escala, y al blanqueo del dinero proveniente de dicha actividad, cuyos principales responsables estaban asentados en varias localidades de la Costa del Sol y Ceuta. El líder del grupo (Mounir Abdelkader Mohamed E.) cumple en la actualidad una condena de veinte años de prisión, impuesta por la Corte de Apelación de Tetuán en mayo de 2004 por los delitos de homicidio, asociación de malhechores y tráfico de drogas. La organización canalizaba los beneficios obtenidos del narcotráfico en el sector inmobiliario y financiero de la Costa del Sol. Para ello utilizaban un entramado societario formado por sociedades mercantiles españolas y gibraltareñas, controladas todas ellas por distintos miembros de la organización. A su vez, estas sociedades estaban asesoradas por varios despachos de abogados de la Costa del Sol, que fueron los encargados de su constitución. Las empresas compraban solares, construían inmuebles actuando como promotoras y transmitían la titularidad de las viviendas de una sociedad a otra. La autoridad judicial decretó el embargo preventivo de numerosos bienes inmuebles (valorados es un total de 10.500.000 euros) y depósitos de varias cuentas bancarias (con valor de 470.430 euros) a lo largo de la Costa del Sol. Entre las propiedades embargadas cabe destacar las siguientes:

- En la Urbanización Pirámides en Mijas-Costa, diecinueve viviendas en altura, diecinueve plazas de garaje y catorce trasteros. Todo ello valorado en cinco millones setecientos nueve mil novecientos veinticuatro euros (5.709.924€).

- Finca en la urbanización "Los Tilos” (Mijas-Costa) valorada en 150.000 euros.

- Finca en la urbanización "Vistaverde" (Mijas-Costa) valorada en 120.000 euros.

- Finca en la urbanización "Las Alamedas" (Puerto Banús, Marbella) valorada en 1.500.000 euros.

\footnotetext{
${ }^{28}$ Dirección General de la Policía, Nota de prensa, 21 de mayo de 2005.
} 
- Vivienda unifamiliar en la urbanización "Riviera del Sol" (Mijas-Costa) valorada en 450.000 euros.

- Vivienda I-S-2 en la urbanización "Pueblo los Olivos" (mijas-Costa) valorada en 180.000 euros.

- Apartamento en el edificio "Saladito II" (Mijas-Costa) valorado en 120.000 euros.

\section{Operación Ballena Blanca ${ }^{29}$}

El Cuerpo Nacional de Policía desarrolló durante más de diez meses de 2005 una amplia y compleja operación contra el blanqueo de capitales procedentes de actividades ilegales de diferentes grupos organizados transnacionales. La operación bautizada como "Ballena Blanca" ha sido una de las más importantes emprendida en nuestro país contra el lavado de dinero. El dispositivo contó con la participación de más de 300 agentes policiales pertenecientes a muy diversas unidades, con la colaboración de Interpol y Europol. Las actuaciones policiales tuvieron lugar en diferentes provincias españolas, como Málaga, Alicante, Cádiz y Granada, e igualmente se practicaron investigaciones en Holanda y Rusia. El blanqueo estimado supera la cifra de 250 millones de euros. Entre los numerosos y valiosos efectos intervenidos hay que destacar 251 fincas inmobiliarias a lo largo de la Costa del Sol, 42 vehículos de alta gama, dos aeronaves valoradas en 1.200.000 euros cada una y una embarcación de 6,5 metros de eslora. En una segunda fase de la operación se procedió a nuevas detenciones, entre ellas la del alcalde de Manilva (Málaga), lo que elevó a 57 el número de detenidos a fecha de octubre de 2005. La nueva fase de la investigación se centró en el incremento del valor de los terrenos situados en el cortijo "La Parrada", en Manilva. Estos terrenos fueron reclasificados en el año 2.003 de suelo rústico a urbanizable no programado y, posteriormente, en 2.004 se incrementa su coeficiente de edificabilidad casi al doble del inicial. Todo ello se realiza en el marco de unos convenios urbanísticos firmados entre el Ayuntamiento de Manilva y la sociedad Royal Marbella Estates S.L., propiedad de los imputados en la Operación "Ballena Blanca". Los registros practicados en los domicilios de los detenidos y en las sedes sociales de las empresas relacionadas permitieron intervenir documentación y efectos que corroboran los indicios apuntados en los informes policiales. Además se incautó gran cantidad de dinero en efectivo, cerca

${ }^{29}$ Dirección General de la Policía, Nota de prensa, 12 de marzo de 2005.

Revista Española de Investigación Criminológica 
de 800.000 euros, que según los informes policiales se hallaban repartidos en bolsas en las viviendas del alcalde y de su cuñado, junto a otros efectos valiosos. Actualmente, la Operación Ballena Blanca se encuentra a la espera de celebrar el juicio.

\section{Operación Malaya ${ }^{30}$}

El 30 de marzo de 2006 se hizo pública la operación 'Malaya', que conllevó por primera vez en la democracia de España la disolución de un ayuntamiento (el de Marbella); casi todos sus representantes municipales fueron detenidos en distintas fases de la operación. La investigación tuvo su origen en unas declaraciones del jefe del Servicio jurídico de Urbanismo del ayuntamiento cuando testificaba en otra causa sobre la gestión urbanística del municipio; como consecuencia de ellas, el juez instructor del caso, el magistrado Torres, requirió en noviembre de 2005 el inicio de las investigaciones. Tras cuatro meses de escuchas telefónicas los investigadores se percataron de la existencia de un complejo entramado societario con más de 120 sociedades instrumentales que eran utilizadas presuntamente por el ex asesor de Urbanismo, Roca, quien, pese a no ocupar cargo electo en la corporación, controlaba las decisiones políticas y económicas del consistorio. Se analizó su entorno más cercano, las personas que habían integrado o integraban la corporación local y aquellas que ejercían actividades profesionales y comerciales con el consistorio.

La operación policial se compuso de tres fases: En la primera fueron detenidas 29 personas en Marbella, Madrid y Murcia, entre ellas, el supuesto cerebro de la trama de corrupción, Roca, la alcaldesa, Yagüe y la primera teniente de alcalde, García Marcos. A finales de junio de 2006, agentes de la Dirección general de la Policía detuvieron a 30 personas más en varios puntos de España dentro de la segunda fase: Entre la lista de arrestados había13 ex concejales del ayuntamiento de Marbella y más de una decena de constructores y promotores. La trama de corrupción marbellí salpicó, así, a importantes empresarios de la construcción en Andalucía. Esta segunda fase fue posible tras el estudio de la documentación obtenida en los registros de dependencias municipales de Marbella y otros inmuebles y de las cuentas intervenidas en la primera fase. El 14 de noviembre de 2006 se orquestó la tercera fase de la operación con la detención de 11

\footnotetext{
${ }^{30}$ Ver prensa local (Diario Sur, Diario Málaga Hoy, La Opinión de Málaga) y nacional (El País, El Mundo, La Vanguardia, ABC) entre el 30 de marzo de 2006 y el 15 de abril de 2008.
}

Revista Española de Investigación Criminológica

Artículo 5, Número 6 (2008) $\quad$ www.criminología.net

ISSN: $1696-9219$ 
personas más, entre las que se encontraban siete empresarios, un funcionario judicial y el director de una entidad bancaria en Marbella.

La policía bloqueó en conjunto más de un millar de cuentas bancarias, efectuó innumerables registros y se incautó de bienes y de dinero en metálico por valor de más de 2.600 millones de euros. La recalificación de terrenos, la concesión de licencias, la puesta en marcha de subastas y concursos públicos amañados para favorecer a empresarios amigos a cambio de millonarias comisiones y regalos parecen ser el modus operandi. Hoy por hoy, la mayor parte de los detenidos se encuentran en libertad algunos tras haber pagado cuantiosas fianzas-. Tal es el caso del presunto cerebro de la trama, Roca, quien tras haber pagado una fianza de un millón de euros, quedaba libre tras 748 días de prisión preventiva. En la actualidad el procedimiento judicial se encuentra en la fase de declaración indagatoria. Una treintena de procesados han comparecido ante el nuevo juez encargado de la causa, Óscar Pérez. Los que han declarado niegan haber recibido o pagado, según el caso, dinero de o a Roca. Algunos de ellos incluso han asegurado haber sido 'coaccionados' en su primera declaración.

\section{Operación Hidalgo ${ }^{31}$}

El 17 de abril de 2007 Marbella volvió a protagonizar una ambiciosa operación policial contra el blanqueo de capitales. A finales de 2005 la Udyco-Costa del Sol iniciaba una macro-investigación que propició la detención de veintitrés personas. Entre los detenidos figuraban cuatro notarios, dos economistas de una asesoría fiscal y un reguero de empleados y testaferros vinculados en mayor o menor medida a la trama. En diciembre del pasado año se archivó la imputación de cuatro fedatarios públicos y cinco empleados. Se mantienen acusadas al menos una veintena de personas, entre ellos el abogado cordobés Cruz-Conde, en libertad bajo fianza de 200.000 euros. Tanto la Policía Nacional como la Fiscalía Anticorrupción situaron el supuesto centro de lavado de dinero en el despacho de abogados Cruz-Conde, el cual estaba presuntamente especializado en la ingeniería financiera para el blanqueo de dinero obtenido a través de actividades delictivas como el narcotráfico, la prostitución y el tráfico de armas. Los bienes incautados incluyeron 553 propiedades inmobiliarias en zonas exclusivas de la Costa del Sol, 92 millones de euros depositados en 632 cuentas bancarias de 22

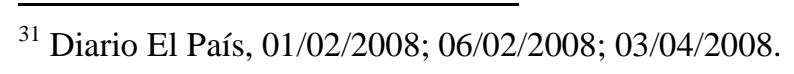

Revista Española de Investigación Criminológica Artículo 5, Número 6 (2008) www.criminología.net

ISSN: $1696-9219$ 
entidades diferentes, 300.000 euros en efectivo, 60 automóviles de lujo y una gran cantidad de joyas.

La instrucción del caso Hidalgo fue iniciada por el juez de Urquía, quien dejó la investigación tras ser apartado del juzgado número 2 de Marbella por su presunta implicación en un procedimiento derivado del caso Malaya. La Comisión disciplinaria del Consejo General del Poder Judicial (CGPJ) le abrió por unanimidad expediente por dos faltas muy graves, y la Fiscalía del Tribunal Superior de Justicia de Andalucía (TSJA) ha solicitado para él tres años de cárcel, 19 de inhabilitación y 213.000 euros de multa en el procedimiento penal que se sigue contra él por prevaricación y cohecho. Según la acusación del fiscal, el juez recibió dinero negro y asesoramiento por parte de Roca para poder vender al mejor precio una vivienda de su propiedad; a cambio, el juez le ofrecía favores o información judicial.

\subsection{ABUNDANTE LLEGADA DE CAPITALES DE DUDOSA PROCEDENCIA}

En cualquier zona que haya actividad económica vinculada a un sector de rápido crecimiento llegarán, sin duda alguna, inversores de las más diversas índoles. La mayoría de las veces se tratará de inversores muy honrados, pero también arribarán inversores faltos de honradez con capitales de dudosa procedencia. En este último caso, esos capitales no siempre procederán de actividades delictivas graves, sino que incluso puede tratarse de capitales ganados de manera ortodoxa pero que buscan eludir el fisco o una fiscalidad ventajosa.

Entre esos capitales afluentes se encuentran los procedentes de grandes fortunas (más o menos confesables), que pueden desembolsar en estos sectores el suficiente capital para seguir generando e incrementando las plusvalías. Por otro lado, los sectores de rápido crecimiento atraen fácilmente a cuantiosos capitales extranjeros que escapan, muchas veces, a la justicia o al fisco de sus países de origen. Por último, estos sectores facilitan oportunidades a quienes intentar colocar o blanquear dinero sucio, proveniente del narcotráfico o de cualquier otra actividad delictiva grave.

Ya hemos apuntado anteriormente el veloz desarrollo del mercado inmobiliario malagueño. Éste y el sector turístico (también de veloz expansión) suelen considerarse 
idóneos para la inversión acabada de describir ${ }^{32}$. Pues bien, en el año 2005, las actividades económicas más importantes de la provincia de Málaga incluyeron la hostelería, la construcción y las actividades inmobiliarias. ${ }^{33}$

En el año 2006 Málaga fue la provincia andaluza donde más sociedades mercantiles se constituyeron (6.663), seguida por Sevilla (5.564) y luego por Granada (2.896). Dentro de Málaga, las ciudades con mayor número de sociedades mercantiles registradas fueron Málaga (2.205) y Marbella (1511). En cuanto al sector de actividad, la mayoría de sociedades constituidas, tanto en Málaga como en Marbella, se concentraron en el sector de la construcción. ${ }^{34}$

Respecto a la inversión extranjera directa en Andalucía durante el año 2006, encontramos que el principal sector de destino de dicha inversión es por mucho, la actividad inmobiliaria y de servicios. ${ }^{35}$ Dentro de los diez principales países inversores en Andalucía, podemos identificar tres paraísos fiscales, a saber, Luxemburgo (el principal inversor), Gibraltar (el quinto inversor) y las Antillas Holandesas (el noveno inversor). Para el conjunto de España, solo encontramos un paraíso fiscal dentro de los diez primeros países inversores: Luxemburgo, posicionado en el sexto puesto. ${ }^{36}$

Efectivamente, cuando comparamos las inversiones extranjeras directas provenientes de paraísos fiscales entre Andalucía y el resto de España, observamos una marcada desproporción. Por ejemplo, en el año 1995, la inversión de paraísos fiscales en España supuso un 3,5\%, mientras que en Andalucía supuso el 40,6\%. En el año 1997, en España fue de 2,94\% y en Andalucía fue de 26,3\%. En el año 2003, la inversión proveniente de paraísos fiscales en Andalucía se redujo al $21,83 \%$ pero comparativamente con el resto de España siguió siendo un porcentaje alto, ya que este último supuso solamente el 2,26\%. En el año 2006, el porcentaje de Andalucía volvió a descender a $11,30 \%$ y el porcentaje para el resto de España se mantuvo en 2,20\%. ${ }^{37}$

\footnotetext{
32 SEPBLAC, "Riesgo de blanqueo en el sector inmobiliario", en Memoria Anual 2006, Servicio Ejecutivo de la Comisión de Prevención del Blanqueo de Capitales e Infracciones Monetarias, Madrid, 2007.

${ }^{33}$ Instituto de Estadística de Andalucía (IEA), Directorio de establecimientos con actividades económicas de Andalucía, Consejería de Economía y Hacienda, Junta de Andalucía, Sevilla, 2005.

34 Instituto de Estadística de Andalucía (IEA), Estadística sociedades mercantiles de Andalucía, Año 2006, Consejería de Economía y Hacienda, Junta de Andalucía, Sevilla, 2007.

${ }^{35}$ Instituto de Estadística de Andalucía (IEA), Inversiones extranjeras directas en Andalucía: Principales sectores de destino de la inversión, Año 2006, Consejería de Economía y Hacienda, Junta de Andalucía, Sevilla, 2007.

${ }^{36}$ Instituto de Estadística de Andalucía (IEA), Inversiones extranjeras directas en Andalucía y España: Principales países inversores, Año 2006, Consejería de Economía y Hacienda, Junta de Andalucía, Sevilla, 2007.

${ }^{37}$ Instituto de Estadística de Andalucía (IEA), Inversiones extranjeras directas en Andalucía: Inversiones directas de paraísos fiscales en España y Andalucía, Serie 1993- 2006, Consejería de Economía y Hacienda, Junta de Andalucía, Sevilla, 2007.
}

Revista Española de Investigación Criminológica

Artículo 5, Número 6 (2008) $\quad$ www.criminología.net

ISSN: $1696-9219$ 
Al comparar las inversiones extranjeras directas ${ }^{38}$ destinadas a la actividad inmobiliaria que se hicieron en España y en Andalucía durante el año 2006, observamos que para Andalucía esa inversión supuso un $76 \%$, mientras que para el resto de España fue del $24 \%$.

El realce de estos datos no supone sembrar la sospecha sobre el conjunto de la inversión extranjera. Sin embargo, todo parece indicar que estos capitales, especialmente los dirigidos a sectores de rápido crecimiento, no son acogidos en el sistema financiero con los suficientes control y transparencia. Baste citar que, según el último informe del Ministerio del Interior, ${ }^{39}$ la evolución de los delitos en materia de blanqueo de capitales se ha incrementado un $140 \%$ desde el año $2003 .^{40}$

\subsection{RÁPIDO CRECIMIENTO DE LA POBLACIÓN, INTENSO ASENTAMIENTO DE POBLACIÓN EXTRANJERA Y ABUNDANTE PRESENCIA DE POBLACIÓN TRANSEÚNTE}

Al 1 de enero de 2006, el total de personas empadronadas en Andalucía se situaba en 7.975.672. Esto le convierte en la comunidad autónoma más poblada de España, por delante de Cataluña, la Comunidad de Madrid y la Comunidad Valenciana.

Dentro de Andalucía, la provincia más densamente poblada la constituye Sevilla (1.835.077). La segunda provincia con mayor índice de población es Málaga (1.491.287), donde el 75\% de los habitantes se ha asentado en la Costa del Sol.

Según el último informe anual de Greenpeace sobre el estado del litoral español, Destrucción a toda costa $2007,,^{41}$ la tendencia de la población andaluza a concentrarse en la franja litoral es imparable. Mientras que la media andaluza de suelo urbanizado en la primera franja de 500 metros supone el 22,2\%, ese porcentaje es del $60 \%$ para la provincia de Málaga (el más alto de Andalucía), llegando incluso al 85\% en localidades como Mijas o al $82 \%$ en Marbella.

\footnotetext{
${ }^{38}$ Del total de países, entre los que se encuentran tanto paraísos fiscales como países con reglamentaciones fiscales más estrictas.

${ }^{39}$ Ministerio del Interior, "La criminalidad en España en 2006: Avance de resultados", Madrid, 2007.

${ }^{40}$ Aunque cabe mencionar que la mayoría de los casos del año 2006 se enmarcaron dentro de la operación policial Malaya (en Marbella).

${ }^{41}$ www.greenpeace.org/espana/campaigns/costas/destrucci-n-a-toda-costa
}

Revista Española de Investigación Criminológica

Artículo 5, Número 6 (2008) $\quad$ www.criminología.net

ISSN: $1696-9219$ 
Todos los municipios de la Costa del Sol han visto incrementada su población en los últimos 15 años, aunque es necesario destacar que Málaga capital no lo ha hecho al mismo ritmo de los otros municipios costeros. ${ }^{42}$

Si bien es cierto que Andalucía no es la comunidad autónoma con mayor número de residentes extranjeros, ${ }^{43}$ cuando uno vuelve su vista a los municipios de la Costa del Sol, se aprecia un alto porcentaje de población extranjera residente empadronada. El gráfico a continuación (Gráfico No. 2) ilustra esos datos de manera más detallada:

Gráfico No. 2. Porcentajes de población española y extranjera en 2006

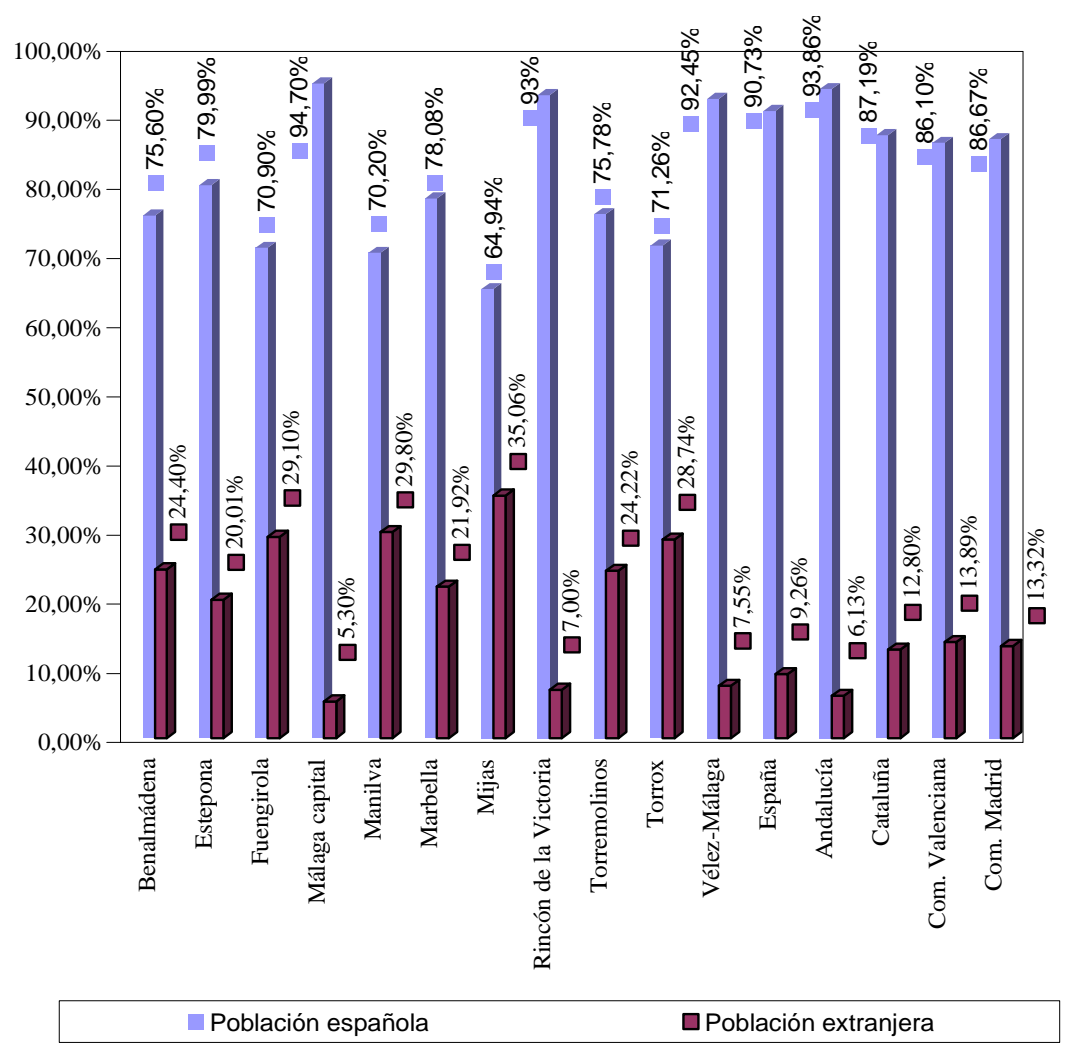

Fuente: Elaboración propia a partir de datos del Instituto Nacional de Estadística (INE) ${ }^{44}$

Por otra parte, en el año 2006 Andalucía recibió más de 25 millones de turistas, de los cuales el 33\% visitó Málaga, siendo ésta la provincia con mayor número de turistas de Andalucía, seguida por Cádiz (16\%), Granada (13\%), Almería (11\%) y Sevilla (10\%). ${ }^{45}$

\footnotetext{
${ }^{42}$ Instituto Nacional de Estadística (INE), Revisión del padrón municipal de habitantes al 1 de enero de 2006, Madrid, 2007.

${ }^{43}$ Según el Instituto Nacional de Estadística (INE) al 1 de enero de 2006 las comunidades con mayor concentración de extranjeros fueron Islas Baleares (16,8\%), Comunidad Valenciana (13,9\%), Murcia (13,8\%) y Madrid (13,3\%).

${ }^{44}$ Instituto Nacional de Estadística (INE), Revisión del padrón municipal de habitantes al 1 de enero de 2006, Madrid, 2007.
}

Revista Española de Investigación Criminológica

Artículo 5, Número 6 (2008) $\quad$ www.criminología.net

ISSN: 1696-9219 
La mayoría de los turistas que visitaron la provincia de Málaga lo hicieron por motivos vacacionales, y en su estancia utilizaron en su mayor parte establecimientos hoteleros. No obstante, el parque de turismo residencial continúa a la alza especialmente en esta provincia. Es decir, Málaga es la provincia con el mayor número de establecimientos dedicados al turismo residencial (47\%), seguida por Granada (19\%) y Cádiz (12\%). ${ }^{46}$ Esto, sin duda, aumenta más, si cabe, la presión urbanística de la zona.

Dada la naturaleza turística de la Costa del Sol, a la población extranjera residente hay que sumar ese importante contingente transeúnte. Estas dos realidades, es decir, el elevado porcentaje de población extranjera residente proveniente de múltiples nacionalidades y la alta proporción de turistas, convierte a la zona en una de constante tránsito de expatriados -itinerantes o no --, ${ }^{47}$ lo cual facilita el anonimato y en el caso de personas que tengan la necesidad de ocultarse, les permite hacerlo sin levantar las mínimas sospechas.

\subsection{INSUFICIENCIAS FINANCIERAS MUNICIPALES.}

Uno de los argumentos recurrentes a la hora de justificar la diversidad y frecuencia de operaciones urbanísticas, muchas veces alejadas de los iniciales criterios de planeamiento, que llevan a cabo los municipios, es la necesidad de obtener ingresos del urbanismo, dada la insuficiencia de los fondos captados por otros rubros presupuestarios.

A este respecto conviene señalar que la capacidad de financiación de un ayuntamiento viene determinada por su ahorro bruto, esto es, la diferencia entre los ingresos corrientes y los gastos corrientes, más las operaciones de capital. Si el resultado es positivo existirá capacidad de financiación, y si es negativo habrá necesidad de financiación.

Pues bien, según el informe sobre la liquidación de los presupuestos de las entidades locales de Andalucía del ejercicio 2002, realizado por la Consejería de Gobernación de la Junta de Andalucía, todas las provincias andaluzas tuvieron un superávit por arriba del $55 \%$ en su saldo presupuestario. En cuanto a la capacidad/necesidad de

\footnotetext{
${ }^{45}$ Instituto de Estadística de Andalucía (IEA), Encuesta de Coyuntura Turística de Andalucía, Consejería de Economía y Hacienda, Junta de Andalucía, Sevilla, 2007.

${ }^{46}$ Junta de Andalucía, Establecimientos turísticos por provincia: Año 2006, Consejería de Turismo, Comercio y Deporte, Sevilla, 2007.

47 Ver, Gomez-Cespedes. A, Prieto del Pino, A. M. y Stangeland, P. Urbanismo, corrupción y delincuencia organizada: Un proyecto de la Costa del Sol, Boletín Criminológico, No. 65, Mayo-Junio, Málaga, 2003.
}

Revista Española de Investigación Criminológica

Artículo 5, Número 6 (2008) $\quad$ www.criminología.net

ISSN: 1696-9219 
financiación, se observó que más de la mitad de los municipios andaluces presentaban una situación de capacidad de financiación. Más precisamente, los municipios de más de 50.000 habitantes presentaban un porcentaje de capacidad de financiación mayor, en concreto un $60,87 \%$, que los municipios entre 5.000 y 20.000 habitantes, con un $50,75 \%$.

Por provincias, fue en Córdoba donde se concentró un mayor porcentaje de municipios con capacidad de financiación, con un 64,38\%. Por el contrario, Sevilla fue la provincia con menor porcentaje de municipios en esa situación, con un 42,31\%. Por otro lado, las provincias de Córdoba, Almería, Granada y Málaga se encontraron por encima del porcentaje medio de municipios andaluces con capacidad de financiación.

$\mathrm{Si}$, por otro lado, lo que nos interesa es conocer el total de los ingresos relativos a la actividad urbanística, tanto los derivados de la normativa urbanística como los de naturaleza tributaria, es necesario sumar los Capítulos I, II, III, V y VI del apartado de ingresos del presupuesto de los ayuntamientos ${ }^{48}$.

Como muestra el Gráfico nº 3, en la provincia de Málaga el porcentaje del presupuesto de ingresos atribuible en buena medida a la actividad urbanística supera al resto de

\footnotetext{
${ }^{48}$ El Cap. I recoge los impuestos directos a percibir por parte de la entidad local, es decir, aquellos que gravan al contribuyente y son satisfechos por éstos de forma directa, y es el que confiere verdadera estabilidad a un Ayuntamiento. El conseguir que los ingresos por este capítulo sean importantes y crezcan garantiza la viabilidad económica de cara al futuro. Este Capítulo se nutre con: El IBI o contribución de inmuebles, que es el impuesto que grava la propiedad inmobiliaria, dividiéndose a su vez en IBI de naturaleza rústica e IBI de naturaleza urbana. El IVTM o impuesto de vehículos, que es el impuesto que grava a los vehículos cuyos propietarios estén empadronados en el municipio. El IAE o impuesto de actividades económicas, que grava las actividades empresariales en función del tipo de actividad. Y el IIVTNU o plusvalía, que grava las transmisiones de bienes inmuebles de naturaleza urbana.

El Cap. II incluye los impuestos indirectos, es decir, los que se pagan a través de una entidad o persona interpuesta que después lo repercute como coste en el precio del producto. El único ingreso del Capítulo es el ICIO, o impuesto de construcciones, que, por las características de crecimiento de la actividad urbanística, es un apartado de bastante relevancia.

El Cap. III incluye las tasas y licencias, los precios públicos, y otros ingresos por sanciones. Contiene un número muy variado de conceptos. Los más importantes incluyen: Las licencias de apertura de establecimiento, las licencias urbanísticas, la ecotasa (en caso de existir), las tasas por la ocupación de la vía pública, las tasas por vado permanente, la tasa de las compañías suministradoras por uso de dominio público (agua, gas, electricidad), los precios públicos por acceso a instalaciones municipales o por participación en actividades de las diferentes concejalías. El Cap. V son los ingresos patrimoniales, es decir, los procedentes de la gestión del patrimonio municipal: Concesiones administrativas, participación en beneficios de empresas públicas, o generación de intereses en cuentas corrientes. Por lo general, los ingresos patrimoniales son poco significativos económicamente ya que los ayuntamientos cuentan con escasas propiedades de las que suelan disponer.

El Cap. VI va referido a ingresos de capital. Se trata, por tanto, de lo que el ayuntamiento espera recaudar como transferencias de otras administraciones o de particulares para construcción de edificios, creación de zonas verdes o realización de otros varios.
}

Revista Española de Investigación Criminológica

Artículo 5, Número 6 (2008) $\quad$ www.criminología.net

ISSN: $1696-9219$ 
provincias andaluzas, con un $63,22 \%$, por encima de la media andaluza, que es de $53,69 \%$

Gráfico No. 3 Porcentaje de ingresos urbanísticos en los presupuestos de entidades locales de Andalucía, por provincias (2002)

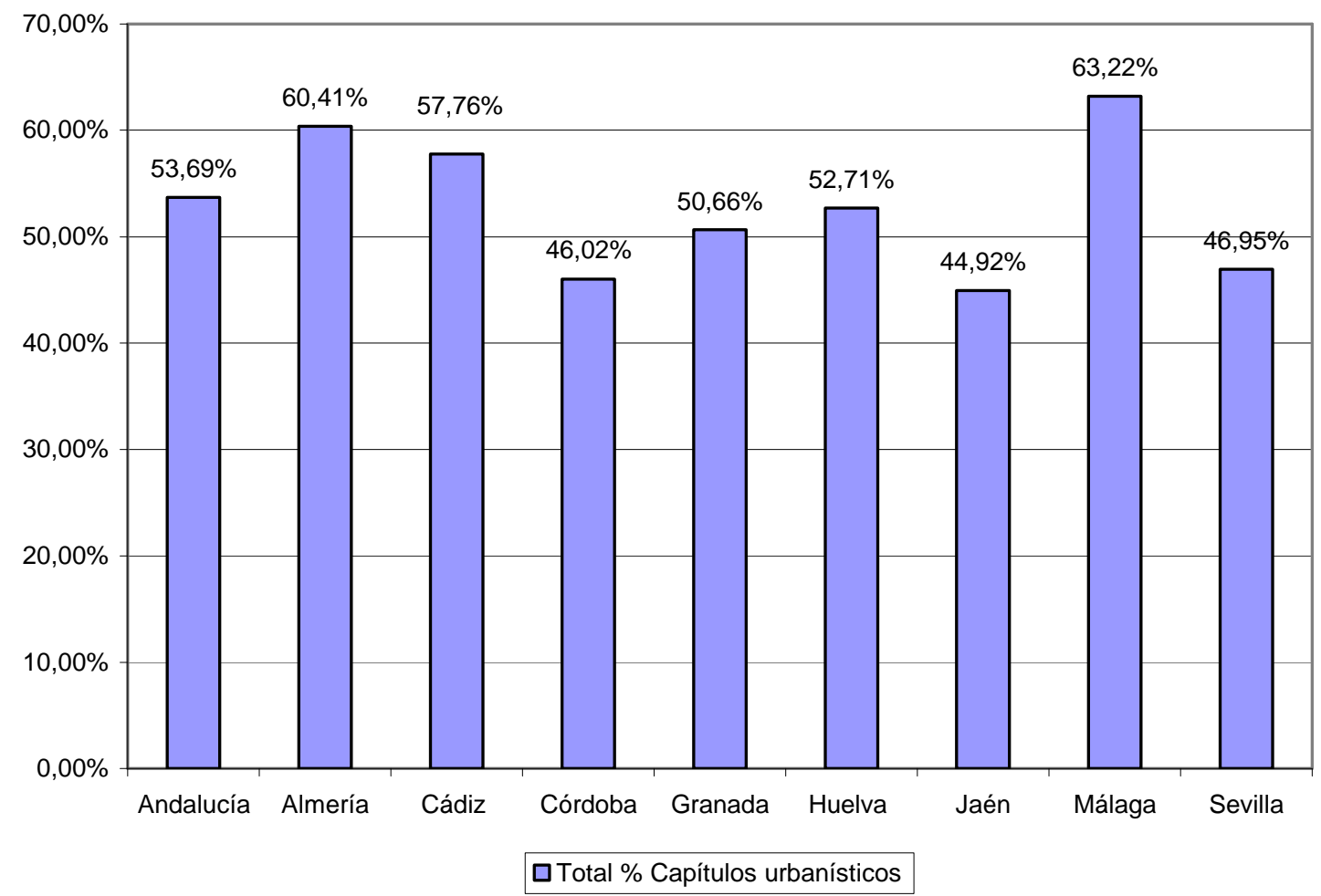

Fuente: Elaboración propia a partir de los datos de la Consejería de Gobernación de la Junta de Andalucía (Ejercicio 2002).

Posteriores estudios en este ámbito deberán confrontar estos datos con los de otras regiones, turísticas o no, del resto de España, así como profundizar en el desglose de esos ingresos y de los gastos que deben afrontar.

\section{INTERVENCIÓN DE LOS PODERES PÚBLICOS EN LA LUCHA CONTRA LA DELINCUENCIA ORGANIZADA Y LA CORRUPCIÓN URBANÍSTICA.}

Para preparar la verificación de nuestra hipótesis ${ }^{49}$ conviene ahora que atendamos a algunas reacciones institucionales que han tenido lugar en los últimos años respecto a la delincuencia organizada en general y la corrupción urbanística en particular.

${ }^{49}$ Véase apartado II.

Revista Española de Investigación Criminológica

Artículo 5, Número 6 (2008) $\quad$ www.criminología.net

ISSN: 1696-9219 


\subsection{RESPUESTAS POLICIALES A LA DELINCUENCIA ECONÓMICA Y}

\section{ORGANIZADA}

Los recursos económicos que destinan los Cuerpos y Fuerzas de seguridad del Estado a la lucha contra la delincuencia económica suelen ser menores que los que se destinan a la delincuencia común. Habitualmente se pone más énfasis en delincuentes y ámbitos que sean más propensos a causar un claro daño material o a sacudir la opinión pública. En el caso de España, se ha constatado que los laxos controles han propiciado una floreciente delincuencia económica relacionada con la corrupción política, estafas colectivas, manipulación de concursos públicos, delitos contra la Hacienda Pública o delitos relacionados con la delincuencia organizada.

No obstante, el creciente número de escándalos financieros y socio-económicos ha estimulado políticas públicas encaminadas a dotar de más y mejores medios a las instituciones con la finalidad de luchar contra este tipo de delincuencia.

Como consecuencia de esos mejores controles se han venido identificando muchos más casos de delincuencia económica. Esto no quiere decir que hoy en día esas conductas delictivas sean más frecuentes. Sencillamente lo que antes era invisible para el común de los ciudadanos cada vez se vuelve más visible gracias a una mayor preocupación, mejores controles e inspecciones más rigurosas. Con todo, cabe mencionar que la efectividad de las políticas de prevención y lucha contra la delincuencia económica dependen mucho del entorno político, empresarial y cultural en el que se pongan en marcha.

El 4 de diciembre de 2004 marcó un punto de inflexión en la agenda del gobierno español contra la delincuencia organizada: Dos personas inocentes morían en un tiroteo perpetrado en una peluquería, en la ciudad malagueña de Marbella. ${ }^{50}$ El sábado por la tarde, el dueño de la peluquería (un hombre italiano de 36 años) y un niño sevillano de 10 años, que estaba de vacaciones con su familia, perdieron la vida en medio de la trifulca. En el tiroteo también resultaron heridas otras tres personas, dos de las cuales eran familiares del pequeño.

Unos pocos días después del incidente, el entonces Ministro del Interior, José Antonio Alonso, anunciaba la puesta en marcha de una unidad policial especializada contra la delincuencia organizada en la zona. Asimismo, el Fiscal General del Estado designaba fiscales anticorrupción en Málaga, Alicante y las Islas Baleares.

${ }^{50}$ Ver, medios de comunicación variados que coincidan con la fecha.

Revista Española de Investigación Criminológica

Artículo 5, Número 6 (2008) $\quad$ www.criminología.net

ISSN: $1696-9219$ 
Desde entonces, el gobierno de España ha venido formalizando un paulatino pero continuo esfuerzo en la lucha contra la delincuencia económica y organizada. Dentro de la estructura de la Dirección General de Policía, se reforzaron las Unidades contra la Droga y el Crimen Organizado (UDYCO) y se crearon los Grupos de Respuesta Especial contra la Delincuencia Organizada (GRECO). Estos últimos se establecieron originalmente en la Costa del Sol y posteriormente se expandieron a las zonas de Cádiz, Valencia, Alicante, Galicia y las Islas Canarias. Por otro lado, dentro de la estructura de la Guardia Civil, se reforzaron las Unidades Centrales Operativas (UCO), responsables de investigar y perseguir delitos graves, especialmente los vinculados a la delincuencia económica y organizada, y se crearon los Equipos contra el Crimen Organizado (ECO). La creación de la Unidad central de Delincuencia económica y fiscal ${ }^{51}$ ha supuesto también otro gran paso en la dirección correcta. Esta Unidad asume la investigación y persecución de las actividades delictivas, de ámbito nacional e internacional, en materia de delincuencia económica y fiscal, así como la coordinación operativa y el apoyo técnico a las respectivas Unidades territoriales. Dependen de esta Unidad: la Brigada de delincuencia económica y fiscal, la Brigada de investigación de delitos monetarios, la Brigada de investigación del Banco de España y la Unidad adscrita a la Fiscalía especial para la represión de los delitos económicos relacionados con la corrupción. Estas brigadas se ocupan de la investigación de los delitos relacionados con la Hacienda Pública, la Seguridad Social, el blanqueo de capitales, los fraudes financieros, delitos bursátiles, estafas, delitos laborales, infracciones monetarias, falsificación del euro y moneda extranjera, así como de brindar apoyo a la Fiscalía especial anticorrupción. ${ }^{52}$

Finalmente, dentro del Ministerio del Interior y bajo el paraguas de la Secretaría de Estado de Seguridad, se creó el Centro de inteligencia contra el crimen organizado (CICO).

\subsection{ACTUACIONES DE LA ADMINISTRACIÓN AUTONÓMICA} ANDALUZA.

Hasta hace muy poco tiempo, el control de la actividad urbanística de la Costa del Sol estaba caracterizado por inspecciones tímidas y poco frecuentes a nivel local. Cuando el cumplimiento de la legalidad se elevaba a instancias autonómicas (Junta de

\footnotetext{
${ }^{51}$ Ministerio del Interior, Nota de prensa, Madrid, 15 de septiembre de 2005.

52 Ver también, Diario Sur, Anticorrupción tendrá mayores competencias en la lucha contra la delincuencia organizada en el litoral, Málaga, 19 de julio de 2006.
}

Revista Española de Investigación Criminológica 
Andalucía) o judiciales (activadas generalmente por particulares), ésta tampoco se subsanaba, cuando menos de manera eficaz.

El largo periodo de tiempo que transcurría hasta la adopción de resoluciones sancionadoras administrativas (especialmente cuando llegaban al ámbito contenciosoadministrativo) ha motivado que la inmensa mayoría de edificaciones ilegales ${ }^{53}$ no sólo se construyeran sino que se habitaran. De esta forma, lo que ha interpretado el ciudadano $^{54}$ es que en materia de actividad urbanística irregular se podía actuar con total impunidad.

La administración autonómica andaluza se fue implicando poco a poco en la prevención y persecución de estas conductas, una vez que empezó a ser manifiesta la importante afección a los intereses generales que estaba produciendo el descontrol urbanístico que se había tolerado durante demasiado tiempo.

La Consejería de Obras públicas de la Junta de Andalucía había abierto, a mayo de 2005, 4.500 expedientes por infracciones de la disciplina urbanística, procediendo a alrededor de un centenar de denuncias penales. De estas últimas más del $40 \%$ afectaban a actuaciones en Marbella. Asimismo, entre los años 1995 y 2006, la administración autonómica impugnó más de 400 licencias de obras sólo en Marbella. ${ }^{55}$ A esa cifra hay que añadir los recursos presentados por asociaciones de vecinos y particulares en ese municipio. Se ha estimado, además, en el avance del nuevo Plan General de Ordenación Urbana (PGOU) que hay 30.000 viviendas ilegales en Marbella ${ }^{56}$.

Aunque ya en 1995 el Consejo de Gobierno de la Junta de Andalucía, mediante Decreto 83/1995, de 28 de marzo, acordó la formulación del Plan de Ordenación del Territorio de Andalucía (en adelante POTA), hubo que esperar hasta noviembre de 2006, 11 años más tarde, para su entrada en vigor (Decreto 206/2006, de 28 de noviembre de 2006). El POTA nació con la pretensión de organizar territorialmente el crecimiento de los municipios andaluces, de forma que equipamientos, servicios e infraestructuras se desarrollasen de modo coordinado y sostenible. Entre otras medidas, el POTA impide que se incremente más de un 40 por ciento el suelo urbanizable del municipio o que se hagan previsiones urbanísticas que supongan un aumento de más del 30 por ciento de la población durante el periodo de vigencia de los nuevos planes generales. Estas

\footnotetext{
${ }^{53}$ Mayoritariamente viviendas, pero también locales comerciales.

${ }^{54} \mathrm{E}$ incluso los propios infractores.

${ }^{55}$ Narváez, D. "La maldición de Banana Beach", El País, 17 de noviembre de 2006.

${ }^{56}$ Diario El País Andalucía 21-4-05, 30-5-05.
}

Revista Española de Investigación Criminológica

Artículo 5, Número 6 (2008) $\quad$ www.criminología.net

ISSN: 1696-9219 
previsiones han suscitado un fuerte rechazo en diferentes sectores sociales $\mathrm{y}$ económicos, lo que ha obligado a matizarlas.

En julio de 2006 la Junta de Andalucía aprobó el Plan de ordenación del territorio (POT) de la Costa del Sol occidental, el cual no ha estado exento de polémica. A finales del año 2006 la Asociación de promotores de turismo residencial y deportivo de Andalucía (Promotor) presentó un recurso contencioso administrativo contra el decreto de la Junta en el que pidió su suspensión cautelar. ${ }^{57}$ El POT también ha sido impugnado por los alcaldes de Estepona y Mijas (ambos socialistas), por lo que a estas alturas es difícil evaluar su eficacia.

Por otro lado, como consecuencia del escándalo de corrupción política del ayuntamiento de Marbella que destapó definitivamente la operación Malaya ${ }^{58}$, en el que el equipo de gobierno municipal al completo se vio, de una u otra forma, involucrado en una extendida red de corrupción, el Consejo de Ministros, debido a una gestión gravemente dañosa para los intereses generales, aprobó el 7 de abril de 2006 un Real Decreto de disolución del Ayuntamiento de Marbella. El Ejecutivo tomó esta decisión tras atender a la solicitud de la Junta de Andalucía y recibir los informes preceptivos del Senado y de la Comisión Nacional de Administración Local, ambos favorables por unanimidad a la disolución. Era la primera vez, desde la instauración de la democracia, que se disolvía un Ayuntamiento.

En consecuencia, y atendiendo a la legislación vigente (Ley Orgánica de Régimen Electoral General y Ley de Bases del Régimen Local) la Diputación de Málaga procedió a la designación de una Comisión Gestora para que ejerciera las funciones de gestión municipal hasta que la nueva corporación, tras la celebración de elecciones, tomara posesión de su cargo. Actualmente el gobierno municipal de Marbella está gobernado por el Partido Popular tras las elecciones de 2007.

\subsection{LA RESPUESTA DE LA ADMINISTRACIÓN DE JUSTICIA.}

Sólo en el año 2003 empieza a haber un perceptible cambio de actitud en la administración de justicia. El Tribunal Superior de Justicia de Andalucía (TSJA), que hasta entonces se había mantenido en gran medida pasivo ante la indisciplina urbanística, emite la primera sentencia condenatoria contra Julián Muñoz (en su cargo

\footnotetext{
${ }^{57}$ Narváez, D., "Los promotores de turismo residencial también impugnan el plan de ordenación de la Costa del Sol”, El País, 19 de diciembre de 2006.

${ }^{58}$ Véase una breve descripción de ella en apartado IV.B.2.
}

Revista Española de Investigación Criminológica

Artículo 5, Número 6 (2008) $\quad$ www.criminología.net

ISSN: $1696-9219$ 
como primer teniente de alcalde de Marbella) por haber concedido una licencia de obras a sabiendas de su ilegalidad.

En el año 2006 el TSJA ha dictado al menos 33 sentencias que anulan licencias de obras concedidas por el Ayuntamiento de Marbella. La mayor parte de esas licencias han sido concedidas a viviendas. La Junta de Andalucía ha pedido al TSJA que ordene la demolición de al menos 334 viviendas, que ya cuentan con sentencia firme.

Según la Memoria anual del Tribunal superior de Justicia de Andalucía correspondiente al año $2006,{ }^{59}$ las diligencias de investigación por delitos urbanísticos abiertas por la Fiscalía de Medio Ambiente, urbanismo y patrimonio histórico del TSJA se triplicaron entre 2005 (con 348 causas abiertas) y 2006 (con 925).

En el mismo sentido, se ha registrado un notable aumento de las diligencias previas incoadas por delitos contra la ordenación del territorio en la provincia de Málaga (Gráfico No. 4), que pasan de 29 en 2002 a 99 en 2006: ${ }^{60}$

Gráfico No. 4. Número de diligencias previas incoadas por delitos contra la ordenación del territorio en la provincia de Málaga

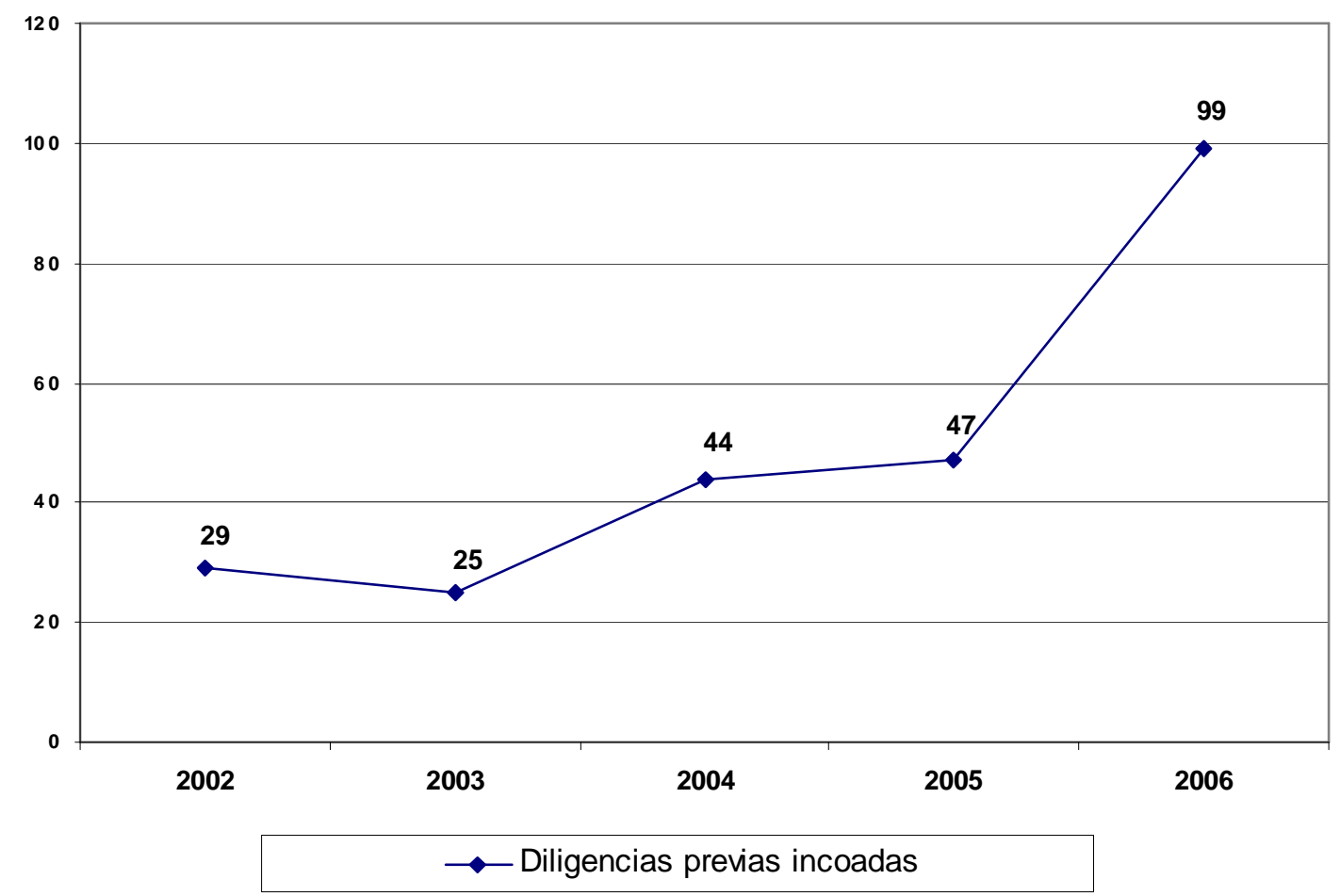

Fuente: elaboración propia a partir de los datos del Ministerio Fiscal

\footnotetext{
${ }^{59}$ Tribunal Superior de Justicia de Andalucía, Ceuta y Melilla, Memoria anual de actividades y funcionamiento Año 2006, Granada, 2007.

${ }^{60}$ Fiscalía General del Estado, Memoria, Madrid, años 2003, 2004, 2005, 2006 y 2007.
}

Revista Española de Investigación Criminológica

Artículo 5, Número 6 (2008) $\quad$ www.criminología.net

ISSN: 1696-9219 


\subsection{LAS ACTUACIONES DE CONTROL Y REGULACIÓN DE LA ADMINISTRACIÓN CENTRAL}

Entre las actuaciones más relevantes de la Administración central cabe citar la aprobación de la Ley 8/2007 del Suelo, que ha adoptado decisiones relevantes sobre régimen y situaciones del suelo y de sus valoraciones, declaraciones de bienes y régimen de incompatibilidades de los representantes locales y asimilados, reservas de suelo para viviendas de protección pública, protección de espacios naturales, y publicidad de los instrumentos de planeamiento, gestión y convenios urbanísticos ${ }^{61}$.

En cuanto a la prevención del blanqueo de capitales por parte del Servicio Ejecutivo de la Comisión de Prevención del Blanqueo de Capitales e Infracciones Monetarias (SEPBLAC), se observa con satisfacción el incremento en el número de asuntos iniciados en los últimos años (Gráfico No. 5).

Gráfico No. 5 Número de asuntos analizados por el SEPBLAC clasificados por asuntos iniciados, terminados y en curso.

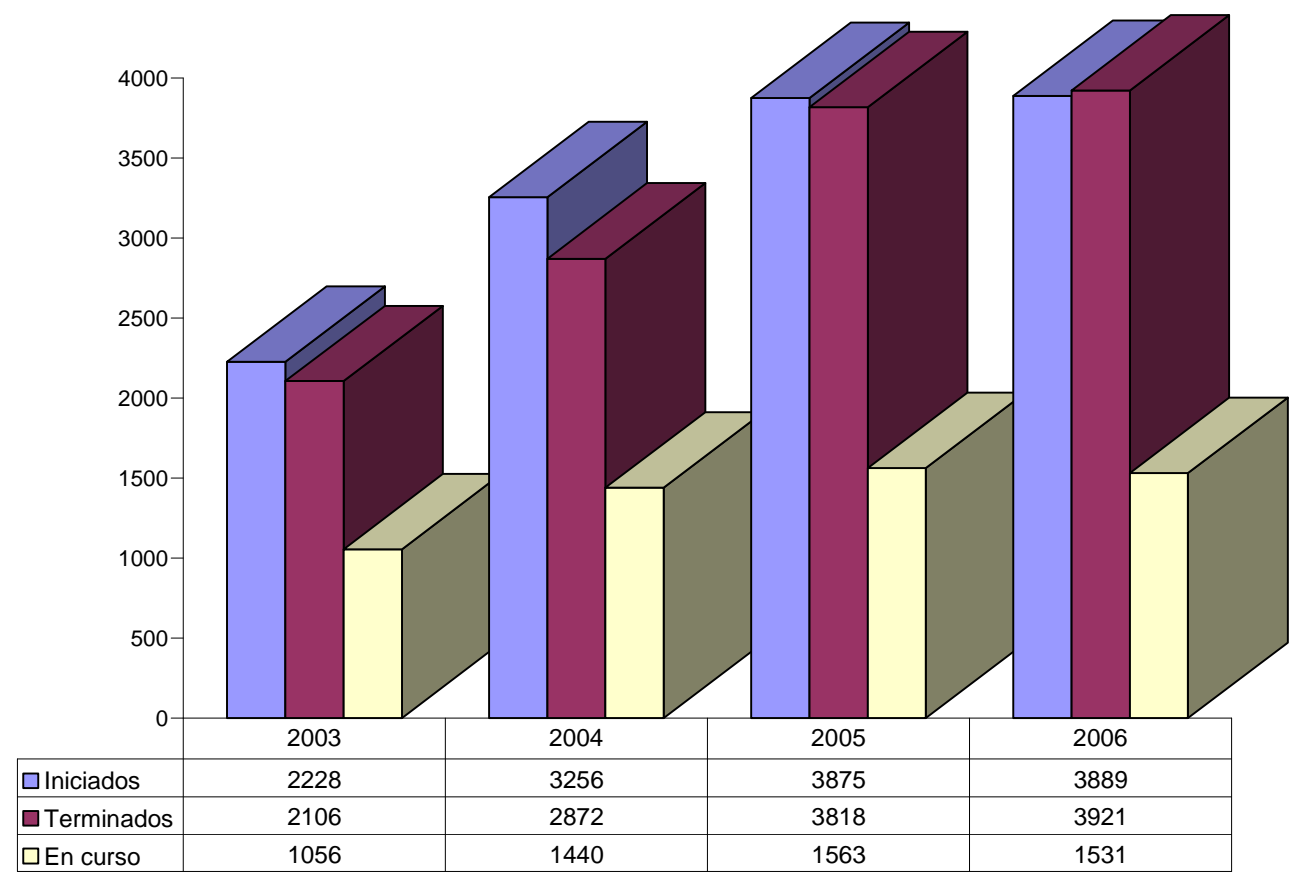

Fuente: Elaboración propia a partir de los datos del SEPBLAC

\footnotetext{
${ }^{61}$ En estos términos, y con una valoración de sus disposiciones y de otras actuaciones que debería emprender la Administración central, véase Grupo de estudios de Política criminal. "Manifiesto sobre corrupción urbanística y otras conductas delictivas relacionadas". www.gepc.es
}

Revista Española de Investigación Criminológica

Artículo 5, Número 6 (2008) $\quad$ www.criminología.net

ISSN: $1696-9219$ 
De todos modos, si bien es cierto que la implantación y desarrollo de procedimientos para la prevención del blanqueo de capitales por parte de los sujetos obligados han evolucionado de una forma positiva en los últimos años, esta tendencia no ha sido homogénea en todos los sectores. Al día de hoy, el sistema de prevención del blanqueo de capitales en España sigue teniendo su pilar fundamental en las entidades financieras, que son, por otra parte, los sujetos más importantes en la implantación de políticas de prevención del blanqueo de capitales. En el resto de sectores, esto es, los sujetos obligados en el ámbito de las entidades no financieras, la situación está lejos de considerarse satisfactoria. $^{62}$ En su descargo diremos que la normativa sobre blanqueo sólo recientemente los ha designado como sujetos obligados, y deberá existir un periodo de transición hasta que se normalice la situación. No obstante, conviene destacar que las decisiones políticas podrían haber sido más aplicadas en esta materia, a la hora de desarrollar los procedimientos necesarios y los protocolos oportunos para el cumplimiento de los deberes de estos sujetos.

A la hora de incorporar nuevos colectivos como sujetos obligados, cabe valorar positivamente la publicación de una Orden ministerial a finales de $2005,{ }^{63}$ que ha sido plenamente operativa en 2006, por la que se crea un órgano de análisis y comunicación centralizado para los notarios; ello va a permitir canalizar de una forma adecuada la colaboración de este colectivo, haciéndole participar de una forma más activa en la prevención del blanqueo de capitales (Gráfico 6).

\footnotetext{
${ }^{62}$ El artículo 2.2 de la Ley 19/1993, de 28 de diciembre, sobre determinadas medidas de prevención del blanqueo de capitales (modificada por Ley 44/2002, de 22 de diciembre; Ley 12/2003, de 21 de mayo; y Ley 19/2003, de 4 de julio) establece como nuevos sujetos obligados a los casinos de juego, auditores externos, contables externos, profesionales independientes del Derecho, asesores fiscales, los que ejerzan actividades de promoción inmobiliaria, agencia, comisión o intermediación en la compra de inmuebles, los notarios, abogados y procuradores cuando participen o actúen por cuenta de clientes en cualquier transacción financiera o inmobiliaria, y las personas físicas y jurídicas que se puedan determinar reglamentariamente.

63 Orden EHA/2963/2005, de 20 de septiembre, reguladora del Órgano centralizado de prevención en materia de Blanqueo de capitales en el Consejo General del Notariado.
} 
Gráfico No. 6 Comunicaciones de operaciones sospechosas por parte de los notarios

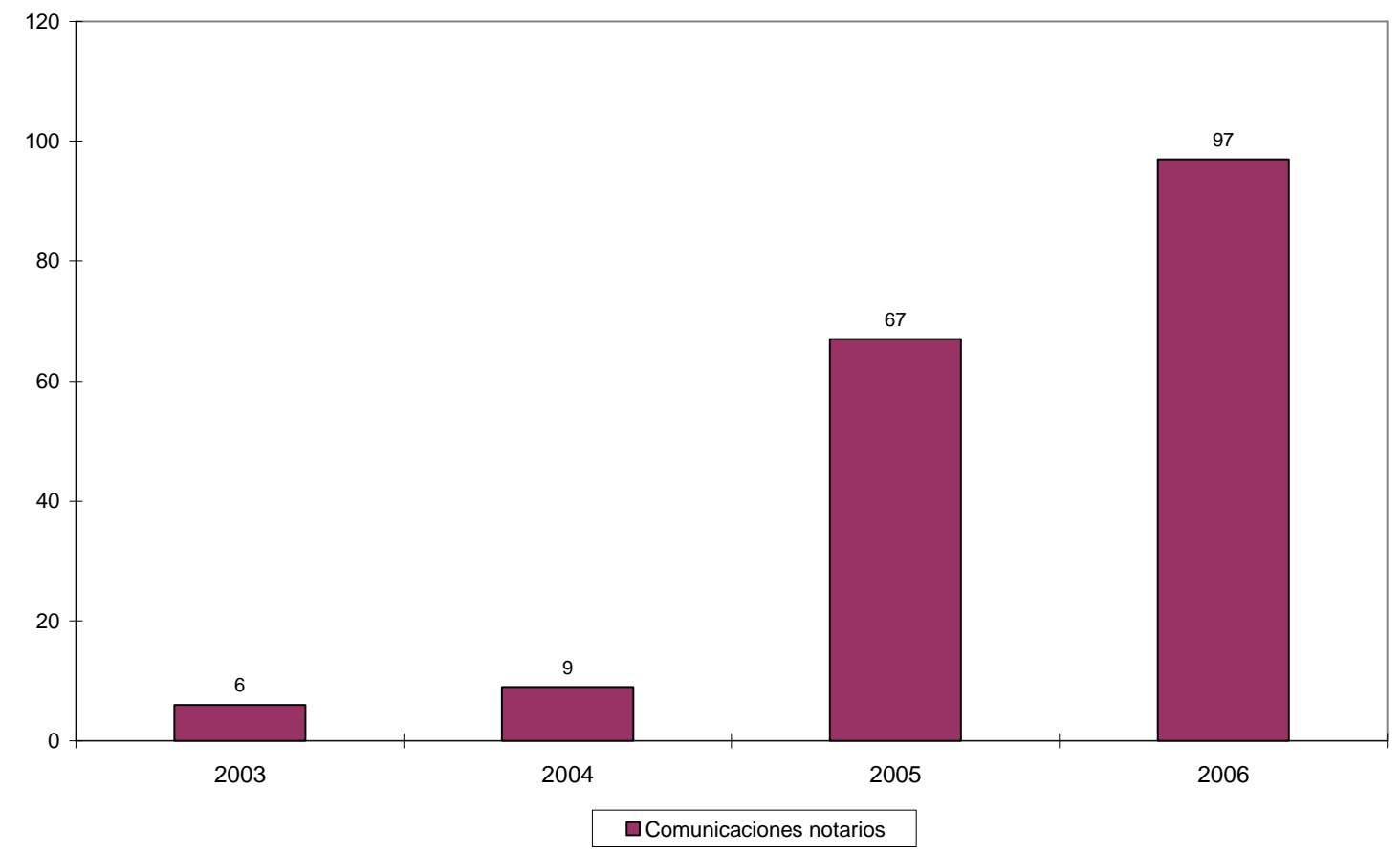

Fuente: Elaboración propia a partir de los datos del SEPBLAC

\section{CONCLUSIONES}

La corrupción urbanística ha arraigado como fenómeno social en la historia reciente de España. Como también ha perdurado una actitud de tolerancia y en ocasiones incluso de condescendencia por parte de los poderes públicos. Para combatir este fenómeno es preciso identificar los factores sociales que lo favorecen, y encontrar una actitud decidida de las instituciones públicas encargadas de combatirlo

A pesar de que la corrupción urbanística es imposible de cuantificar, opinamos que existen una serie de indicadores que nos permiten conocer si este fenómeno se encuentra asentado - en mayor o menor grado- en determinados territorios. En el caso de la Costa del Sol hemos observado que existen una serie de condiciones que podrían promover la consolidación de la corrupción urbanística. Entre otras, hemos destacado en este estudio la rápida evolución del parque inmobiliario, la importante presencia de actividades de delincuencia organizada en la zona, la inversión que esa delincuencia organizada hace en el mercado inmobiliario, la abundante llegada de capitales de dudosa procedencia, la constitución de numerosas sociedades mercantiles instrumentales para el blanqueo de fondos, o el rápido crecimiento de una población multicultural y muchas veces con escaso arraigo. 
También creemos que si los poderes públicos son capaces de identificar esos indicadores y logran incidir significativamente sobre ellos, la corrupción urbanística se podrá reducir de forma importante. Cegados en demasiadas ocasiones por los beneficios económicos que una actividad urbanística descontrolada es susceptible de producir a corto plazo, les ha costado reconocer los graves daños que ella es capaz de causar en bienes fundamentales para la convivencia y en los fundamentos del Estado de Derecho. Finalmente parece que han decidido tomar una actitud más intervencionista.

De este modo, hemos visto que desde el Ministerio del Interior se han aportado más medios para la lucha contra la delincuencia organizada. Algunas comunidades autónomas, como la Junta de Andalucía, se han decidido a ejercer a fondo sus competencias ordenadoras y supervisoras, y la Administración central ha tomado también cartas en el asunto. Del mismo modo, tanto la Administración de Justicia como el Ministerio Fiscal han interiorizado, aunque sea tardíamente, la necesidad de asegurar el cumplimiento de las previsiones legales sobre ordenación del territorio. Es de esperar que estas nuevas actitudes se conviertan en la regla para el futuro, y no en meras actitudes episódicas vinculadas a sucesos escandalosos especialmente llamativos.

Los últimos datos facilitados por el Colegio de Arquitectos de Málaga indican que la construcción de nuevas viviendas en la provincia retrocedió casi un $20 \%$ en los tres primeros meses de 2007. ${ }^{64}$ Creemos que, además de la desaceleración del mercado inmobiliario, las actuaciones de la Junta de Andalucía, el Tribunal Superior de Justicia de Andalucía y el Ministerio Fiscal han jugado un papel determinante en el freno del urbanismo salvaje de la Costa del Sol. Los datos del Colegio de Arquitectos muestran que de ese retroceso sólo se salvan parte de los municipios de la costa oriental y algunos del interior. Es decir, mientras la construcción de viviendas ha descendido en todos los municipios de la Costa del Sol occidental, en algunos municipios del interior esa bajada es casi imperceptible. Por ejemplo, mientras que en Marbella el descenso en construcción de vivienda nueva rondó el 70\%, en Ronda los visados aumentaron un $163 \%$ y en Álora un $468 \%$.

Esto nos plantea la duda de si realmente las actuaciones de los poderes públicos han tenido la capacidad de reducir el problema, o si simplemente el 'problema' se ha trasladado a contextos más favorables. En algunos círculos informados se habla del

${ }^{64}$ Ver datos publicados en el Diario Sur el 17 de abril de 2007.

Revista Española de Investigación Criminológica 
urbanismo salvaje de la segunda franja del litoral. ${ }^{65}$ Pero también se habla de que los capitales que antes generaban riqueza en la Costa del Sol se han visto forzados a trasladarse a otras regiones 'menos fiscalizadas', entre las que podría encontrarse, por ejemplo, la Región de Murcia, que ha venido a sustituir a Málaga en los primeros puestos de la jerarquía de los territorios con mayor carga urbanística.

Comparando la provincia de Málaga con la Región de Murcia es llamativo observar el impacto que han tenido los poderes públicos en el desarrollo de la actividad urbanística.

Para la provincia de Málaga, las líneas de tendencia entre 2002 y 2006 indican una reducción en el número de viviendas iniciadas, a la par que un aumento en el número de diligencias previas incoadas por la Fiscalía General del Estado por delitos relacionados con la ordenación del territorio (Gráfico No. 7).

Gráfico No. 7. Tendencias en el número de viviendas iniciadas y diligencias previas incoadas por delitos contra la ordenación del territorio en la provincia de Málaga

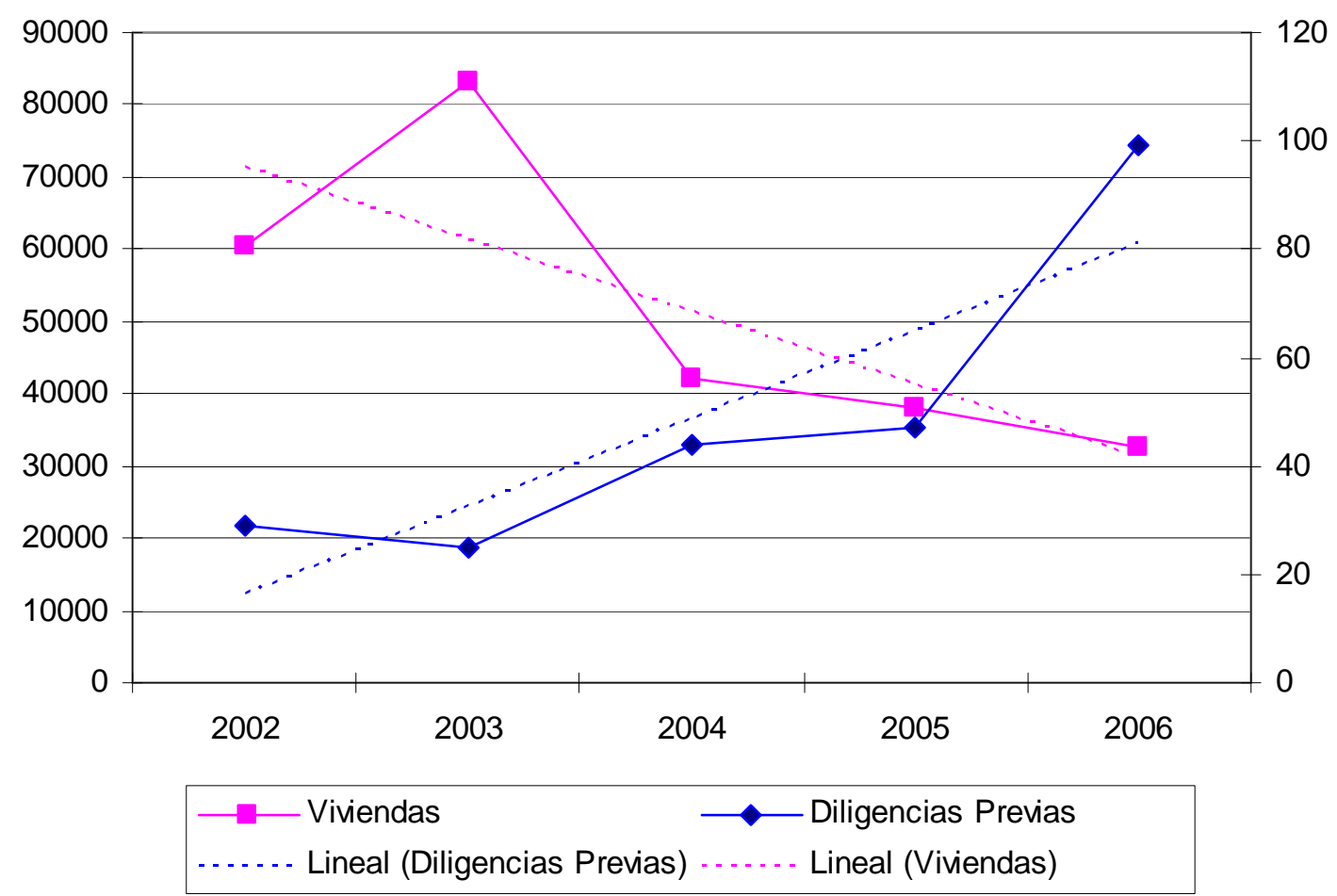

Fuente: Elaboración propia a partir de datos del Ministerio de Vivienda y de la Fiscalía General del Estado

${ }^{65}$ Dónde Ronda y Álora son claros ejemplos.

Revista Española de Investigación Criminológica

Artículo 5, Número 6 (2008) $\quad$ www.criminología.net

ISSN: $1696-9219$ 
Cuando se observa la Región de Murcia en el mismo periodo (2002 - 2006) se advierte justamente lo contrario: Mientras la tendencia de inicio de viviendas se inclina al alza, la tendencia de diligencias previas incoadas por parte de la Fiscalía General del Estado se orienta a la baja (Gráfico no. 8).

Gráfico No. 8. Tendencias en el número de viviendas iniciadas y diligencias previas incoadas por delitos contra la ordenación del territorio en la Región de Murcia

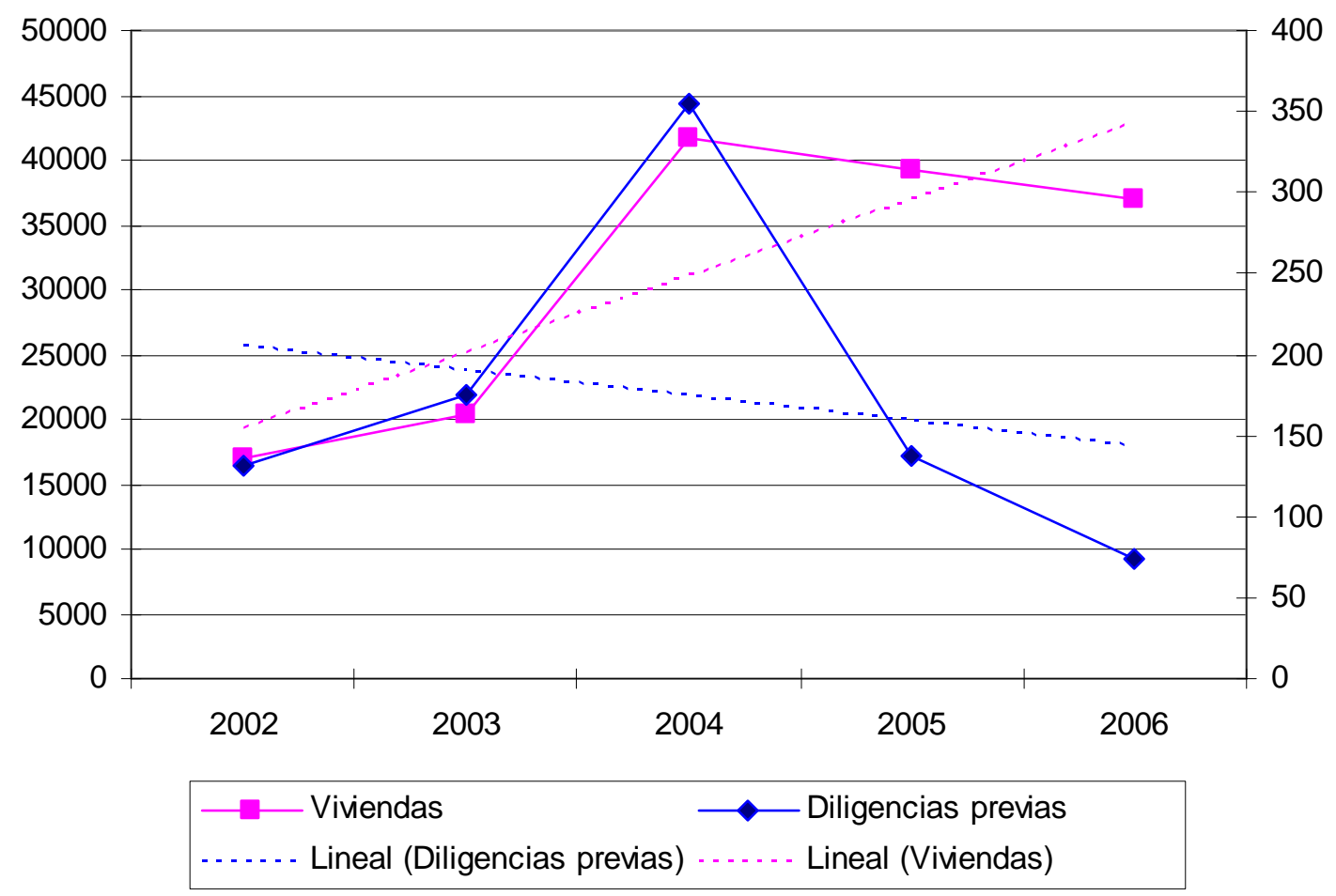

Fuente: Elaboración propia a partir de datos del Ministerio de Vivienda y de la Fiscalía General del Estado

Hasta el momento no podemos saber al detalle qué tanto ha influido el cambio de actitud de los poderes públicos en el control de la actividad urbanística de la Costa del Sol. Sin embargo, es un hecho que la construcción de nuevas viviendas ha descendido de modo importante en la zona. Intuimos que este descenso no puede atribuirse solamente a una desaceleración del mercado. Más bien parece que en la zona se han comenzado a cerrar o dificultar el acceso a espacios vulnerables a la corrupción y especulación urbanísticas y que, a consecuencia de esto, el fenómeno se ha trasladado a otras regiones.

Como decíamos al comienzo de este estudio, esta es una hipótesis que deberá ser verificada en un futuro próximo, cuando se esté en condiciones de analizar con la 
suficiente secuencia temporal los efectos de diferentes actuaciones públicas sobre territorios con indicadores socioeconómicos semejantes. 